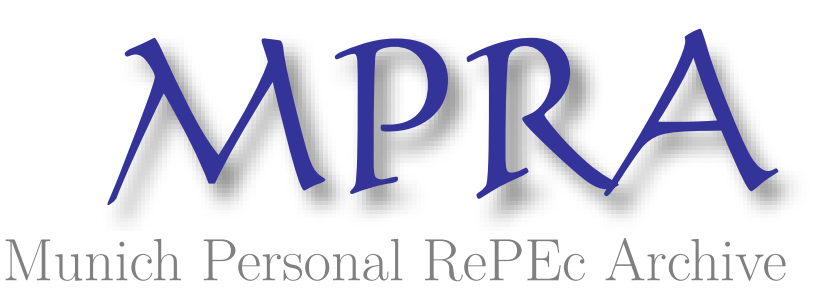

\title{
A New Economics for Modern Dynamic Economies
}

Fusari, Angelo

2016

Online at https://mpra.ub.uni-muenchen.de/74008/

MPRA Paper No. 74008, posted 25 Sep 2016 12:42 UTC 


\section{A New Economics for Modern Dynamic Economies}

Innovation, uncertainty

and entrepreneurship

Angelo Fusari 
In memory of my dear friend Angelo Reati, an important student of economics, and to a very important living student, Clifford R. Wymer, for his invaluable teachings on modelling, simulations and econometric application 
It is becoming increasingly clear that a new economics is required for investigating modern dynamic economies and the coming social world. Important features of those economies, such as innovation, uncertainty and entrepreneurship, are usually considered capitalist features. This may have been true historically, but this book argues that the contrary will be true for the future: the full and efficient operation of those supposed capitalist features will increasingly require the overcoming of capitalist civilization.

In this book, Angelo Fusari constructs a theoretical framework for the interpretation and management of modern dynamic economies which demonstrates that deep institutional transformations are essential if we are to move beyond the current consumer-capitalist age and the age of the domination of financial capital

- A New Economics for Modern Dynamic Economies opens with a consideration of the basic aspects of modern dynamic economies and proceeds to develop a representation of the whole economic system centered on the interrelationships between entrepreneurship, innovation and radical uncertainty in a 'dynamic competition' process. This model provides an explanation of business cycles that largely differs from current explanations as it derives from the notion of dynamic competition. The book is then extended from the sectoral to the micro level and then to the level of the firm. The second half of the book is concerned with operational problems and in particular with the integration of this analysis of cycles with the notion of historical phases of development. The final chapter explores the route of the transition from capitalism to a new economic and social order a transition of vital importance, both for the contemporary world and for the coming world. The book also shows the possibility of a scientific explanation of important ethical pinciples as indispensable to the organizational efficiency of social system: for instance, the necessity and the way to conciliate productive efficiency, social justice and individual freedom.

This volume is of great interest to those who study political economy, macro-economics and economic theory and philosophy. 


\section{Contents}

List of figures $\quad$ xi

List of tables $\quad$ xiii

Preface xiv

\section{PART I}

Theoretical frame

1 Innovation, uncertainty, entrepreneurship: modeling the dynamic process of the economy

1.1 Introduction 3

1.2 The theoretical foundations of our economic analysis 4

1.3 A critical review 14

1.4 Conclusion 28

2 Mainstream economics and heterodox economics:

a misleading controversy - necessary system versus natural system

2.1 Introduction 33

2.2 Some considerations on the method of the social sciences 35

2.3 Limits and omissions of classical natural systems and their similarity with those of neoclassical general equilibrium models 39

2.4 Indispensable extensions of the analysis 42

2.5 Necessity and choice possibility in the organization of the economy: the necessary system 43

2.6 For a new institutionalism, and a last note on the separation principle 46

2.7 Conclusion 47

3 An explanation of economic change and development

3.1 Introduction 51

3.2 The main factors of economic change and development 53 
viii Contents

3.3 The model 61

3.4 Numerical simulations 78

3.5 A micro version of the model 87

3.6 Conclusion 87

Appendix 89

4 A micro representation of the innovation-adaptation mechanism driving economic dynamics

4.1 Introduction 97

4.2 Entrepreneurship and its endogenization 98

4.3 The adaptive model and its convergence to a stationary state 104

4.4 The model with innovation and adaptation: a currently disregarded cyclical interaction 114

4.5 An extension of the model to multiple goods and oligopolistic markets 126

4.6 Conclusion 127

Appendix 129

5 An analysis on the theory of the firm: organizational forms and dimensions

5.1 Introduction 137

5.2 Some significant aspects of the debate on the firm 138

5.3 Ambivalence in the theory of the firm 141

5.4 Optimization in the presence of true uncertainty 143

5.5 From individual firms to large-scale managerial firms:

stimulants and boundaries to their dimensional growth 146

5.6 Some details on the factors counteracting the boundaries to the dimensions: the objective or institutional nature of the boundaries 151

5.7 Conclusion 153

6 Radical uncertainty, dynamic competition and a model

of the business cycle. The implications of a measure

and an explanation of what is supposed immeasurable

and unexplainable

6.1 Introduction 157

6.2 Clarification of notions: uncertainty versus expectations 158

6.3 An analytical framework for the study of survey answers and the measurement of radical uncertainty

159

6.4 Evidence from the business surveys 162

6.5 Uncertainty, innovation and business cycle 178

6.6 Conclusion 185 



\section{PART II}

Problems of political economy: the need for reformations

7 An overview of the economic process

7.1 Premise 193

7.2 A fundamental misunderstanding 193

7.3 Cycles and phases of development 195

$7.4 \mathrm{On}$ the process of social and historical development: the time arrow 197

7.5 Conclusion 199

8 The role of demand in contemporary economics: theoretical and operational ambiguities and misunderstandings

8.1 Introduction 201

8.2 Formulation of the problem 202

8.3 The foundation of demand-led models on an important hypothesis about the labor market 203

8.4 Consequences and meanings, for demand models, of the nonoperation of the postulate of residuality of real wages 206

8.5 Ambiguities of the current analyses centered on demand: a scheme devoted to better considering previous arguments and some clarification on inflation 209

8.6 Conclusion 212

9 Economic dualism: a model concerning Italy

9.1 Introduction 216

9.2 The bitter fate of economic planning and the phenomenon of dualism 216

9.3 Formulation of the model 220

9.4 Results of estimation 225

9.5 Stability and sensitivity analysis 227

9.6 Predictive performance of the model 228

9.7 Conclusion 229

10 Money, interest rate and financial markets

10.1 Introduction 232

$10.2 \mathrm{~A}$ brief review on the role and operation of money from the 1930s to the present time 232

10.3 The implications on financial activities of endogenous money variations 234

10.4 What about the present? 236 
$\mathrm{x}$ Contents

10.5 The rate of interest 238

10.6 A proposal on the organization of financial markets 240

10.7 Conclusion 242

11 The ethical dimension: creativity and social justice

11.1 Introduction 245

11.2 Diversity and equality: a fundamental proposition 245

11.3 Equality and diversity in ancient civilizations 247

11.4 The advent of capitalism 248

11.5 Some useful teachings: Keynes and Schumpeter 249

11.6 Entrepreneurship, innovation and effective demand 250

11.7 Conclusion 251

12 Toward a noncapitalist market system: spontaneous order and organization

12.1 Introduction 253

12.2 Historical sketch of the market 254

12.3 The capitalist market 257

12.4 Some other basic organizational needs of the present and coming economic systems 260

12.5 Conclusion 266

Name index 


\section{Figures}

3.1 Production of consumer goods $\quad 80$

3.2 Production of new capital goods $\quad 80$

3.3 Employment (demand for labor): consumer goods

3.4 Productivity of radical process innovation for the individual $\begin{array}{ll}\text { innovator: consumer goods } & 81\end{array}$

3.5 Diffusion of radical process innovations: consumer goods 81

3.6 Productivity of labor: consumer goods $\quad 82$

3.7 Labor productivity from incremental innovations: new consumer goods $\quad 82$

3.8 Radical uncertainty: consumer goods $\quad 83$

3.9 Excess of entrepreneurship: consumer goods $\quad 83$

3.10 Excess of entrepreneurship: new consumer goods $\quad 84$

3.11 Price of consumer goods $\quad 84$

3.12 Price of new consumer goods $\quad 85$

3.13 Rate of profit: consumer goods $\quad 86$

3.14 Markup: consumer goods $\quad 86$

4.1 Total available and excess of entrepreneurial skill; variance
of profit rates across firms

4.2 Labor productivity by firm, in natural logarithms 112

4.3 Total output and employment, in natural logarithms 113

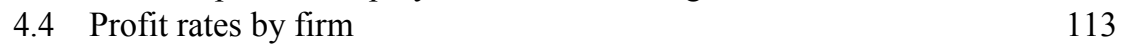

$\begin{array}{lll}4.5 & \text { Sensitivity of convergence } & 114\end{array}$

4.6 Total available and excess of entrepreneurial skill; variance of profit rates across firms $\quad 120$

$\begin{array}{ll}4.7 & \text { Labor productivity by firms, in natural logarithms } \\ & 121\end{array}$

4.8 Output and employment of all firms and of innovative firms,

$\begin{array}{lll}4.9 & \text { Profit rates by firm } & 122\end{array}$

4.10 Labor productivity by firm, in natural logarithms 124

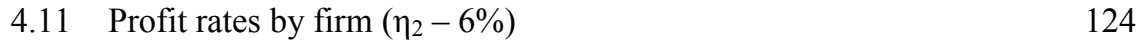

4.12 Labor productivity by firm, in natural logarithms $\left(\eta_{2}+6 \%\right) \quad 125$

$\begin{array}{ll}4.13 \text { Profit rates by firm }\left(\eta_{2}+6 \%\right) & 125\end{array}$

6.1 First indicator of uncertainty by classes of business size 165 

xii Figures

6.2 Second indicator of uncertainty by classes of business size 165

6.3 Expectations and realizations differences 166

$\begin{array}{ll}\text { 6.4 Radical uncertainty and confidence indicator } & 168\end{array}$

$\begin{array}{ll}\text { 6.5 Usual confidence indicator and that corrected by } & \\ \text { radical uncertainty } & 169\end{array}$

6.6 Current overall order books, up 171

$\begin{array}{ll}\text { 6.7 Current overall order books, same } & 172\end{array}$

$\begin{array}{lll}\text { 6.8 Current overall order books, down } & 172\end{array}$

6.9 Current overall order books, balance 173

6.10 Current stock of finished products, up 173

$\begin{array}{ll}6.11 \text { Current stock of finished products, same } & 174\end{array}$

$\begin{array}{ll}\text { 6.12 Current stock of finished products, down } & 174\end{array}$

$\begin{array}{ll}6.13 \text { Current stock of finished products, balance } & 175\end{array}$

$\begin{array}{ll}6.14 & \text { Production expectations, up } \\ 6.15 & 175\end{array}$

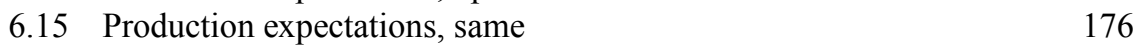

6.16 Production expectations, down 176

6.17 Production expectations, balance 177 


\section{Tables}

3.1 Propensity to innovate during the phases of the long wave 59

3.2 The main features of the long wave 61

A.1 Initial values of the endogenous and of exogenous variable $\quad 89$

$\begin{array}{lll}\text { A.2 Parameters } & 90\end{array}$

A.3 Hypotheses underlying the simulations 90

A.4 First appearance of radical process and product innovations 91

4.1 Parameters identical across firms 111

$\begin{array}{lll}4.2 & \text { Other data used by simulations } & 111\end{array}$

$\begin{array}{lll}4.3 & \text { Parameters } & 120\end{array}$

4.4 Sensitivity of the indicated variables with respect to $6 \%$ positive $\begin{array}{ll}\text { and negative variation of } \eta_{2} & 123\end{array}$

$\begin{array}{ll}6.1 & \text { Survey answers of two periods } \\ 6.2 & 160\end{array}$

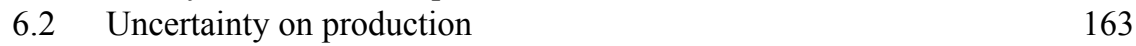

6.3 Uncertainty on delivery orders and demand 163

$\begin{array}{lll}6.4 & \text { Uncertainty on prices } & 163\end{array}$

$\begin{array}{ll}6.5 & \text { Uncertainty on cost of financing } \\ 6.6 & 164\end{array}$

$\begin{array}{lll}\text { 6.6 Uncertainty on liquidity assets } & 164\end{array}$

6.7 General level of uncertainty, derived by the aggregation of the previous series 164

6.8 Model in Volterra's form 181

6.9 Model in Volterra's form 182

6.10 Model in Volterra's form 182

6.11 Model with the term PA in equation 2 instead of PA*u 183

6.12 Model in Volterra's form 183

6.13 Model with the term PA in equation 2 instead of PA*u 183

9.1 Estimated adjustment parameters 225

9.2 Estimated elasticities and growth rates 226

$\begin{array}{lll}9.3 & \text { Stability and sensitivity analysis } & 227\end{array}$

9.4 Ex post root mean square errors of dynamic forecasts 229 


\section{Preface}

This book arises out of a sustained critical reflection on (and dissatisfaction with) the current state of economic thought - a reflection based upon the systematic confrontation of current economics with the content of economic reality. The book attempts to construct a theoretical framework more adequate than current formulations for the interpretation and management of the economy.

Part I considers basic aspects of modern dynamic economies that are largely ignored by the dominant schools of economic thought, or are at best mentioned merely for the sake of the appearance of completeness, and which, in addition, are largely misunderstood by the dissenters from the dominant doctrines. Chapter 1 is an introductory chapter. It discusses some of the most important variables of modern dynamic economies and the explanatory power of their interactions and directs some criticisms at past economic thought for completely or partially ignoring these variables. Chapter 2 deepens those criticisms by turning to the method of economic and social science; we show that the analysis of social reality needs a third method that is in addition to and distinct from those of the natural sciences and the logicformal sciences - a method that is founded on completely different postulates, rules and classifications. On such a basis, this chapter dis-cusses some contemporary conflicts among schools of thought, particularly the opposition between mainstream and heterodox economics, which troubles current economic theory and even the teaching of eminent scholars. Chapter 3 offers a representation of the whole economic system centered on the interrelationships between entrepreneurship, various kinds of innovations and radical uncertainty in a 'dynamic competition' process. The devised model has been formalized at the maximum level of sectoral disaggregation (one sector for each specific good) and simulated with a restricted number of sectors. It provides an explanation of business cycles that largely differs from current explanations, as it derives from the notion of dynamic competition and shows that the duration of cycles, especially the long waves, is shortened by the intensity of dynamic competition as a result of the values of some parameters. Chapter 4 extends the analysis and formalization from the sectoral to the micro level. Chapter 5 develops the micro analysis with regard to the firm. Finally, Chapter 6 presents a substantial broad-ening of our understanding of radical uncertainty, the most typical and the most embarrassing element of economic dynamics, and probably, notwithstanding its 
growing importance, the most misunderstood. The final section of this chapter presents the formalization and estimate of a model of the (intermediate) business cycle based on the interaction between innovation and radical uncertainty. This cycle and those considered in Chapter 3 are expressions of the theorized dynamic competition process - that is, they are implied by the exposition of the mechanism of this process; as such, they differ from the various types of cycles considered by current economics.

Part II is mainly concerned with operational problems. It commences with Chapter 7, which gives an overview of the economic process that integrates our analysis of cycles with the notion of historical phases of development. This integration is aimed at allowing an exploration of economic and social processes capable of improving our understanding of the course of history, in particular, of the direction of the ever-changing economic world in the wake of the emergence of new basic structures that will require new policies and organizational forms. Precisely, the changes of organizational procedures (as required by the new general conditions of development generated by economic dynamics), which mark the passage from one historical phase to another, will facilitate understanding of the advent of new features of cycles that develop over the course of history, as well as the content and administration of future economic order and development. This introductory chapter guides the development of the whole of Part II. It seems to us that the absence in economics and social studies of a grafting of cycles on historical phases and of an explanation of cycles based on the phenomenon of dynamic competition constitute two fundamental lacunae of economic theory; this is indeed a great drawback if we wish to be able to understand the changing content of cycles over the course of history and also the variable institutional (and ethical) needs of societies over time to manage their coming into being.

Chapters 8 and 9 are concerned with the role of demand and the question of economic-social and territorial dualism. Chapter 10 treats of money and financial variables, which play very important roles in any characterization of the globalization process; the analysis of money also offers a continuation of key themes treated in the earlier discussion of demand. Chapter 11 concerns the ethical dimension in economics on which the globalization process today confers a growing importance. The final chapter explores the content of a possible transition from capitalism to some new economic and social order (building on some anticipations of this matter set out in the two previous chapters); such a transition would appear of vital importance, both for the contemporary world and the coming world.

A number of chapters make substantial use of mathematical formalization and modeling. The intention is to make their content stringent and to clarify how mathematical specification is able to act as an important tool in representing and explaining economic processes; it is to be hoped that this clarification will contribute to overcoming the growing mistrust for mathematics by many economists and students of the social sciences, a mistrust caused by frequent oversimplification through mathematics and the resulting distortions, mainly in the work of neoclassical economists. In particular, Chapter 3 and, even more so, Chapter 4 should not be 
read as affected displays of mathematical virtuosity but taken, rather, as providing a demonstration of the flexibility of mathematical formalization in representing with realism important aspects of economic dynamics. Moreover, we set out some considerations on the appropriate use and limitations of econometrics in the study of modern dynamic economies and societies as characterized by growing nonre-petitiveness of events.

However, mathematical formalization is not a dominant feature of the book; history, sociology and political science are not passed over, but rather they play an important role in the proposed theoretical development of economics.

The chapters in Part I theorize on the present, but in doing so take care that the foundations of the theory rest on solid ground and, as such, are able to illuminate the future. But the past is not ignored, especially in Chapter 2, which criticizes previous theoretical approaches. Chapters 8 and 9 in Part II are, for the most part, concerned with the past, while the three chapters that follow move from important traits of the past and the present economic situation to set out, as just alluded to, some proposals envisaging necessary organizational forms concern-ing the future.

I first began to intensify my meditation on economic problems at the beginning of the 1970s as a result of my professional work on Italian economic programming at ISPE (Institute of Studies for Economic Programming), which was then the main Italian research institution on this subject. A real theoretical and operational enthusiasm then operated within the programming circles; it was an enthusiasm fueled by the participation of renowned Italian and foreign economists and soci-ologists in the preparation of the national economic plans and by frequent erudite debates, meetings and conferences enlivened by the charisma of important stu-dents and Nobel laureates.

My growing doubts as to the validity of various celebrated theories first arose by way of comparison between factual reality and the enunciated programmatic principles. Subsequent experience in macro and sectorial planning instilled in my mind the conviction that great misunderstandings were caused by profound equivocations on method. The upsetting evidence of those equivocations and misunderstandings has driven me to a laborious process of reflection and inquiry into the methods of economics and the social sciences, a work that has ultimately come to constitute the core of my scientific production and publications.

This book is intended to offer some basic lines of a new economics that is appropriate for investigating modern dynamic economies and the coming social world. Important features of those economies, such as innovation, uncertainty and entrepreneurship, are usually considered as essentially capitalist features. This is true from a historical perspective, capitalism having been the parent of the modern dynamic economies and societies. Nevertheless, we shall see that the contrary is true for the future: the full and efficient operation of those supposed capitalist features will increasingly require the overcoming of capitalist civilization. At any rate, it is impossible, or, at the very least, it will be extremely troublesome, to pro-ceed without building up the institutional transformations (functional imperatives) caused by the transitions through the historical age of conflictual-consumeristic 
capitalism and the present age of financial (global) capitalism, as explained in the last three chapters of this book.

Some repetitions that occur over the course of the chapters should be met with patience on behalf of the reader, for they reinforce appreciation for, as well as deepen understanding of, crucial aspects of our analysis in addition to allowing an independent reading of each chapter. 


\section{Part I}

\section{Theoretical frame}




\title{
1 Innovation, uncertainty, entrepreneurship \\ Modeling the dynamic \\ process of the economy
}

\begin{abstract}
This chapter focuses on some crucial variables that express (and determine) the content and the functioning of modern dynamic economies. These variables, the most important of which are innovation, radical uncertainty and entrepreneurship, are usually ignored and even treated as annoyances by traditional economists. Yet the interactions between them, and the corresponding notion of dynamic competition, provide the core of our theoretical construction. In consequence, our construction provides the substance for, and indeed points to, some potentially stimulating criticisms of the main orthodox and heterodox economic theories as well as a new design for political economy. This opening discussion is thus intended to prepare the road for the whole theoretical and empirical construction that follows.
\end{abstract}

\subsection{Introduction}

This chapter discusses some misunderstandings that afflict economic thought in an attempt to contribute to their clarification. They concern three important aspects of the economy tightly linked each other: innovation, uncertainty and entrepreneur-ship. Their interaction will be represented here through the notion of dynamic competition.

This feature of the economy is inconsistent with the analytical apparatus of mainstream economics that, as a consequence, has yielded completely delusive results despite the use of sophisticated techniques and procedures. The situation is made worse by the fact that the various branches of heterodox economics, even if animated by an acute and growing dissatisfaction toward mainstream economics, have not offered a satisfactory treatment of the three aspects but only a fragmented analytical panorama. A study of the matter must meet a complex and encroaching intellectual apparatus that has been built over time on methodological bases that, although fashionable, are substantially misleading. This will oblige us to start from some consideration on method but is limited here to what is absolutely indispens-able. The chapter is articulated as follows.

Section 1.2 sets out at first some brief considerations on method, mainly addressed to economics. Then it presents a simple and concise representation of the productive process that is mainly centered on the phenomenon of dynamic competition. It follows an analysis of uncertainty and innovation and a treatment of fixed capital, which is a protagonist of dynamic motion and is deeply concerned with innovation and uncertainty. The section ends up with a brief description of the dynamic and cyclical motion of the economy. These analyses will provide the foundations of subsequent development. Section 1.3 expounds a critical review, starting with some main omissions and equivocations of general economics. Afterward, we discuss two enlightening approaches that provide the premises for a satisfactory treatment of dynamic competition; this allows showing a missing ring, represented by the postulate of immeasurability of radical uncertainty and the impossibility of its explanation, a postulate that strongly opposes the necessary 
theoretical clarifications and advancement. We then suggest that the current insistence on bounded rationality, polemically with the neoclassical theory of perfect

knowledge, has accentuated the difficulty of formalizing dynamic competition and caused various equivocations on decision making. Some consideration on institutions, with reference to the theory of the firm, will follow. The hope of these analyses is to stimulate some implementation of the economic research along lines that have been insufficiently deepened until now.

\subsection{The theoretical foundations of our economic analysis}

\subsubsection{Some consideration on method: a clarifying example}

The reader of this chapter may ask why, if our focalization on the importance of dynamic competition - and specifically a measure and explanation of radi - cal (endogenous) uncertainty - is right, economists have dedicated so little attention to the matter. To answer this, a brief treatment on method, specifi - cally referred to economics, is required. This important subject will be better analyzed in Chapter 2. ${ }^{1}$

The persistent acceleration of social change has determined a growing consciousness of economists and other social students of both the erroneousness of the postulate of repetition (and mere acceptance of the given situation) typical of the method of natural sciences and of the importance to consider appropriately the investigated reality. Unfortunately, this realization has led to an excess of analyti-cal fragmentation and hence a lack of comparability among theories; a main cause of that is the frequent denial of the feasibility of shared methodological rules that make possible the confrontation among students and the control of theoretical hypotheses. As a consequence, many economists proceed freely; so an inconclu-sive and sterile pluralism is born, consisting in a variety of incompatible positions unable to interact.

An important aspect of the situation is economists' disregard for the explanation and measurability of uncertainty. Proper (or radical) uncertainty contradicts the postulate of the repetition of phenomena, implied by observational method, thus making itself unacceptable to the followers of that method. A frequent and easy way to set aside radical uncertainty is using 'abstract rationality' criterion and/or referring uncertainty to known subjective or objective distributions of probability, as is typical of the economics of perfect knowledge. Unfortunately, heterodox economics (and its criticism of mainstream economics), which strongly insists on radical uncertainty, the implied limits of knowledge and the connected notion of bounded rationality, has been conquered by the ideas of the immeasurability and nonexplanation of uncertainty.

To complete this analysis, it is necessary to remember the main methodological considerations that induce us to insist on some current misunderstandings on uncertainty, innovation and entrepreneurship. Unlike the natural sciences, social sciences concern a reality that is generated by man. This is obvious. What is not so obvious is the implication that social sciences, in order to properly investigate this reality, must focus on the better ways to organize social relations, that is, the institutional pillars of these. 
The investigation on the organizational form of society may usefully start from some basic aspects of the considered reality (the character of the existing general conditions of development) and deduce their implications. In fact, those basic aspects require some organizational forms of the economic system coherent with them, the absence of which would weaken the competitiveness and sustainability of economic order. Uncertainty and the connected phenomena of innovation and entrepreneurship represent some of those organizational features and premises.

Keynesian economics clarifies this question well, but such clarification has not been pointed out by the numerous debates on Keynesian teaching. The core of such teaching can be outlined as follows:

- A main aspect of the general conditions of development of modern age is endogenous radical uncertainty caused by innovation.

- Uncertainty and the state of expectations imply, mainly through their influence on investment, that effective demand be either insufficient or in excess relative to production and hence reduce output or stimulate inflation.

- It follows that the control of effective demand is a main 'organizational require-ment' or necessity of modern economies.

- This implies some important programmatic, normative and institutional prescriptions, such as redistributive policies, welfare state, fiscal and monetary policies and deficit spending.

As we can see, Keynesian theory starts from an important feature of the modern general conditions of development, that is, radical uncertainty and the possible deficiency of effective demand, and deduces some crucial implications or orga-nizational necessities. Unfortunately, Keynesian teaching limits itself to such an aspect. Moreover, it concerns macroeconomics, thus omitting the microeconomic aspects of modern economies linked to uncertainty, mainly entrepreneurship and the explanation of innovation.

Let us reassert that the analysis that will follow emphasizes the relationship among entrepreneurship, innovation and uncertainty and their implications. The functional and organizational requirements implied by these phenomena are not deterministic entities that are automatically engendered by the economic process; they may be absent or badly reflected within the social system. Specific attention may be needed to remedy this deficiency.

\subsubsection{Dynamic competition and economic development}

Let's give now a schematic representation of economic process.

In a market economy, production is a way to get profit in the context of dynamic competition. This statement is referable to private and public entrepreneurship since, in any case, profit rate matters for accountability purposes, that is, to mea-sure an entrepreneur's degree of success.

Economic phenomena, as resulting from some actions and decisions taken independently by a plurality of agents, generally assume different and even opposite 


\section{Theoretical frame}

contents from expected results. It is mistaken to think this fracture (between actions and results) may be remedied through a centralized system of decision making. Centralization only makes sense in a stationary society; it cannot face creative and innovative events, as these imply a qualitative leap with respect to the previous situation. In fact, the centralization of decision making is inconsistent with a world of beings endowed with limited capabilities but who are able to evolve. It tends to suppress novelties as it is almost impotent toward them and hence suffocates innovation and creativity, pushing economic systems toward a stationary state.

Advancement in knowledge, as well as in material and spiritual conditions, proceeds by trial and error, through a plurality of intuitions, decisions and initiatives in competition with each other. This requires the building of institutions able to stimulate personal qualities, especially creativity, to evaluate the achieved results and to facilitate coordination among the plurality of decisions. At the basis of these organizational requirements there is the limitation of knowledge, that is, uncertainty.

A qualitative and decisive leap in human history took place when the economy began to display an extraordinary ability to stimulate and govern innovation and took central stage in the social system. The modern age started at that point. All seems to indicate that the economic system will preserve this strategic position, even if flanked in the future by some other social subsystems. In fact, the economy is well equipped to operate in the presence of uncertainty and to stimulate explo-ration; in other words, it is well equipped to govern and feed the dynamism of social process. In particular, the economy has developed an efficient mechanism of the coordination of individual initiatives that, in addition, strongly stimulates innovation, gets information on tendencies at work and is clever in evaluating the degree of appropriateness of decision making and can adjust this as needed. Such a mechanism of production is represented by the competition in the market and the search for profit; it is a mechanism that warrants the adjustment to unpredict-able events and attributes with inflexibility the merit and responsibility for success and failure in the entrepreneur's main function, that is, in meeting unpredictable events. The economy has also developed the key agent of such a mechanism, the entrepreneur, who meets and, through innovation, stimulates uncertainty with the purpose of making profit.

It is our hope that this brief description has shown some key elements for the representation of the dynamic competition process: the market warrants the coor-dination over time and space of individual initiatives, in particular demand and supply, while the entrepreneurial arbitrage, aimed at getting profit from market disequilibria, tends to erase profit opportunities deriving from 'errors' and mar-ket disequilibria. If entrepreneurs limited themselves to arbitrage, very low profit would result. But the entrepreneur can recreate disequilibria, uncertainty and the connected profit opportunities through innovation; thus even scarcely creative entrepreneurs can profit both through imitation of innovations and because these recreate spaces for arbitrage.

The described innovation-adaptation mechanism is not limited to the economy but constitutes a basic expression of social-historical processes and hence is an 
important analytical tool for the interpretation of those processes. ${ }^{2}$ But it is the economy that exhibits the best and more efficient innovation -adaptation mechanism that, in addition, can be formalized and investigated in quantitative terms. The starting point of the dynamic process is innovation; but the entrepreneurial arbitrage and imitation of innovations push toward a stationary state, thus reducing uncertainty and the opportunities of arbitrage and imitation of innovations; this stimulates the introduction of novelties and hence a new rise of disequilibria and uncertainty that discourage further innovation, both directly and due to the advent of new profit opportunities through arbitrage. So, we have an incessant disequilibrating-equilibrating economic process pushed by the adaptive and inno-vative search, discovery and creation of profit opportunities.

We call this form of competition, which strongly characterizes economic action and production in modern age, the notion of dynamic competition; it is hinged on entrepreneurial innovative and adaptive action directed to take advantage of exist-ing opportunities and create new ones, and it results from the interaction between entrepreneurship, innovation and uncertainty. One main task of economics should be the combination of those components in a unitary process that is able to explain innovation, uncertainty and entrepreneurship.

This dynamic competition is the basic mechanism of economic development and would be impossible in the absence both of uncertainty and the connected limitation of knowledge. Moreover, we shall see later that uncertainty is the crucial variable explaining both the demand and supply of entrepreneurship, and, in fact, this is inseparable from the phenomenon of radical uncertainty. Therefore, an accurate treatment of uncertainty is of central importance, and we will soon show that some misunderstandings in this regard are a main impediment to an acceptable specification of the notion of dynamic competition.

The current omission or fragmentation of the analysis of dynamic competition is a great lack of economics. This competition completely differs from that usually represented through the inclination of demand and supply curves: in fact, it causes day-by-day changes in those curves, creates new ones and influences costs, quality of products and so forth. The usual theoretical treatment of production based on the notion of production function well expresses the dimensions and the seriousness of the analytical lack of (and disregard for) dynamic competition. In fact, the production function approach is only apparent in accordance with evidence; in effect, that accordance is warranted only in a stationary economy. In incorporating a production function in dynamic analysis, various and sophisticated modifications of that function have been developed, mainly the inclusion of human capital and exogenous or endogenous technical progress. But no satisfactory results have been achieved along this line. A production function is useful if it is limited to cost specification. But other elements, in addition to cost, influence production. These elements can be taken into account only through the help of the notion of dynamic competition.

We hope that the previous considerations on the importance of such phenomena will stimulate the production of statistical data on innovation, entrepreneurship and radical uncertainty - the basic components of the process of dynamic competition so as to remedy a quite incredible lacuna of statistical economics in the field. 


\section{Theoretical frame}

\subsubsection{Radical uncertainty - the mistaken postulate of the impossibility of its explanation and measurability: the difference between uncertainty and expectations}

This subsection specifically considers the question of uncertainty. The probability that, in the throwing of a well-balanced die, a determined face appears is undoubtedly one in six and expresses probabilistic certainty. This objective probability does not involve capabilities and does not express uncertainty; it is the same for everybody. On the contrary, uncertainty involves capabilities. Some people have better knowledge than others, some are cleverer, and some can adapt themselves to new events. Subjective distributions of probability are not identical for everybody, and they involve capability. But the subjective probabilistic approach presumes that the decision-maker knows the probabilities of the considered events; instead, true uncertainty is an expression of the degree of ignorance. Speaking of expecta-tions, we shall see better that subjective probability has nothing to do with true (or radical) uncertainty, even if an eventual measure of this uncertainty should help to define subjective probability or expectations. Radical (or true) uncertainty simply expresses the lack of knowledge.

A growing number of students define uncertainty as each aleatory phenom-enon that cannot be included in the notion of probability. They also maintain that uncertainty is impossible to measure and hence impossible to insure. This notion of uncertainty, apparently simple and clear, implies serious errors and confusions on measurability and insurability. Some clarifications are, therefore, indispensable.

In deciding on future events, an entrepreneur must formulate expectations.

Some of the corresponding probability distribution will be well defined and the properties of the distribution either known or able to be specified to sufficiently good accuracy; others will not and will be more or even highly subjective. It is very important to measure the degree of reliability of the expectations, which does not correspond to a well-defined probability distribution and hence probabilistic certainty. The degree of variability, or the dispersion, of expectations expresses radical uncertainty. It is senseless to deny the possibility of measuring and explain-ing such uncertainty; as a matter of fact, entrepreneurs must pay a great attention to get that measure. Expectations lacking in a measure of their reliability may be very deceitful.

It is important to underline that the question of insurability has no relevance in discussing uncertainty. Probably all possible events are insurable at a price; whether insurance is used depends on the cost and the assessment of the effect of having or not having it. Insurance companies may dislike treating very high degrees of uncertainty, but this has nothing to do with the impossibility of measur-ing uncertainty that, in fact, is supposed to be very high. It is well known that vari-ous hazardous events are insured even though they cannot be expressed through probability distributions allowing a precise measure of the risk corresponding to them. Insurance does not strictly need probability calculus; in fact, it was practiced much before such calculus was invented. Fire risks or theft and shipwreck risks are roughly classified to make possible their consolidation. Their insurance is not 
based on some accurate probability calculation; nevertheless, it is made convenient by its low cost relative to the damages that the occurrence of those events would cause.

On the contrary, it does not make sense to insure the casual events concerning dynamic competition among firms; nevertheless, the entrepreneur takes a great care to measure the variability of expectations (or uncertainty), as just seen. The imposition by law of insurance for the benefit of creditors of bankrupt firms may be imagined, but not insurance aimed at avoiding bankruptcy; that contradicts dynamic competition, as we shall see soon. The insurance of firms' losses is made senseless not by the impossibility of measuring business uncertainty but by the peculiar content of the dynamic competition process. As we know, this process is made active by the search for profit opportunities, that is, the tendency to use entrepreneurial skills to get profits. But insurance against firms' losses tends to erase profit and implies the renunciation of the entrepreneurial role, making the entrepreneur similar to a foolhardy gambler; to cover insurance costs, he would look for ill-considered opportunities of profit and this would cause the rise of insurance costs, distort entrepreneurial function and hence push the gambler out of the market.

In conclusion, the uninsurability of firms' results is not a consequence of the impossibility of measuring uncertainty, but of the fact that businesses need the competence - that is, the judgment, intuition and responsibility - of decisionmakers when facing uncertainty. The insurance of firms' losses would distort the role and use of those indispensable skills, so that these false entrepreneurs would be defeated by the competition of more genuine entrepreneurship.

Radical uncertainty is a result of innovation in the context of the dynamic competition process. ${ }^{3}$ This is the key of its explanation that, in turn (and as we shall see), allows the explanation of entrepreneurship and its role, use and formation. More precisely, uncertainty is explained by radical process innovations and their diffusion, radical product innovations and incremental innovations.

Economics and empirical research attempt to remedy the supposed immeasurability of uncertainty through the estimation of expectations. But, even if uncertainty implies expectations, their estimation is a completely different matter from the measure of the degree of uncertainty. Expectation, and the notion of subjective probability (i.e. the degree of confidence that an agent attributes to the fact that some event may happen), expresses hope that is more or less well founded, while uncertainty simply indicates a limitation of knowledge so that its measure simply gives the degree of ignorance. Expectation is, in a certain sense, a pretension of knowledge, while uncertainty is an expression of cognitive impotence. Due to these differences, the effects of uncertainty on economic variables are different from those of expectations; the two take different roles in the economic process.

Economics has proposed some analytical expressions to estimate expectations: static expectations, adaptive expectations and rational expectations. These expressions give some arbitrary and oversimplified formalization. The study of their accuracy, for instance a sensitivity analysis of the effect of changes or errors in the parameters of those expressions, is referable to uncertainty. Expectations probably 


\section{Theoretical frame}

represent the most important aspect of entrepreneurship; their content results on entrepreneurial coup d'oeil, intuition, talent and experience, so that each entrepreneur has his proper expectations. Uncertainty is another thing; it has to do with the variability of results and it can (and must) be explained and measured. We shall see that the postulate of the immeasurability and unexplainability of uncertainty causes great equivocations and deprives economists of an indispensable variable to represent the economic process with realism.

\subsubsection{The problem of fixed capital}

The stock of fixed capital is heavily influenced by innovation and by radical uncertainty, and it therefore deserves special treatment in a study focused specifically on these two phenomena - all the more so as present-day analyses of fixed capi-tal mostly ignore them. In particular, the disregard of both those crucial aspects is complete in the formalized general models of the economy hinged upon the accumulation process, such as the Walrasian model with capital accumulation and

Leontief's input-output dynamic model.

To make evident this limitation (and disregard), it may be useful to dedicate some detail to one of the most sophisticated analyses of the subject. Piero Sraffa and John von Neumann have inculcated the conviction that the problem of fixed capital can be adequately treated only by recourse of joint production models. But it seems that despite their formal, mathematical elegance and complications, these models offer no advantage in the treatment of fixed capital.

The claim that joint production models (i.e. the expedient of including capital goods inherited from the past among the products of the current year) permit the exact solution of the problem of depreciation is unfounded. It would be so only if technique were immutable. But this is not so. The desperate battle of the neoRicardian economists, with their command of linear algebra, against the difficulties of joint production in the name of the theory of capital resembles an attempt, with daring architectonical solutions, to construct an elegant building with founda-tions laid on clay. The clay that destabilizes the foundations of the neoRicardian analysis is the fact of technical progress, because when there is technical progress, the rate of obsolescence has a decisive impact on the depreciation table. ${ }^{4}$ In this case, the neo-Ricardian method of calculating depreciation and the economic life of machinery by taking the technical coefficients, the physical life of machines and the distribution quotas of income as givens is incapable of yielding correct and reliable results.

Treating fixed capital through the joint production model is, in principle, no way superior to the Leontief method of defining a matrix each year of the amounts to depreciate alongside those of fixed and circulating capital. Indeed, this second method is simpler and corresponds better to real-world practice.

On the connected theme of the choice of technique, the neo -Ricardian school again seems to err on the side of excessive virtuosity. That is, the criteria of technological choice that it develops are solidly grounded only insofar as they deal with the problem of 'truncation,' that is, determining the economic life of 
machinery (but here too they fall into the difficulties set out previously). The neo-Ricardian school posits that the technology considered has already been introduced (and the only question is to determine how to depreciate it) and that it is perfectly known. But when the question is whether or not to adopt a new technology, a number of complications arise that severely diminish the significance of the criteria for choice that the neo-Ricardians set out. Precisely, once a technol-ogy has been introduced there is no turning back, even if the circumstances that induced the choice cease, wholly or in part, and the technology to be introduced is almost never perfectly known, given that the proportions between its input ratios generally develop and evolve in the course of its creation and depend on a large number of circumstances that are variable from case to case and with which the businessman must grapple.

The foregoing means that technological choices cannot be made on the basis of the analysis of the 'factor price frontier,' since that frontier is unknown. This implies that it is unadvisable to base decisions on small variations in profitability.

The decision to introduce a new technology will be made only if the prospective benefits are sufficiently great. In particular, these decisions will be made according to much more empirical criteria of valuation than the neo-Ricardians would maintain. ${ }^{5}$

In the presence of radical uncertainty (in this case, due to technical progress), the prices that are set necessarily rest on fragile bases, given the hypothetical nature of the costs for amortization. In these conditions, one way of dealing with uncertainty (if the entrepreneur is endowed with a good nose for business and com-mon sense) is to set a period for recovering the capital invested and to distribute over that period the depreciation/amortization quotas, either rigidly or flexibly, depending on the circumstances, the policies adopted and so on. Competition will ensure that this calculation by businessmen will approximate reality fairly closely over the entire period considered when, naturally, the extra profits from innovation

(i.e. from successfully dealing with the sort of uncertainty posited by Knight or Schumpeter) are considered as components of price. ${ }^{6}$

Our formulation, in Chapter 3, of a model of dynamic competition that is mainly based on the interaction of innovation, uncertainty and entrepreneurship presents a simple specification in considering the impact of innovation and uncertainty on the stock of fixed capital. We express this through an adjustment equation to produc-tion, corrected with a term representing the negative impact of radical uncertainty on that adjustment. If we substitute for the term production in this equation its explanatory variables, we can see the crucial effect on the variation of the capi-tal stock, entrepreneurship, profit rate, and hence innovation, and again radical uncertainty. Thus we obtain a notion of fixed capital plainly linked to the critical phenomena that influence it in a dynamic economy that is powerfully affected by innovation and uncertainty.

For its part, gross investment, considered as a component of demand, is explained in the model in Chapter 3 by the variation of net capital stock, plus the replacement of the worn capital, plus obsolescence (of existing equipment) due to the diffusion of radical innovations concerning capital goods. 


\section{Theoretical frame}

\subsubsection{Innovation, endogenous time and the dynamic motion of the economy: the cycles of process and product}

The exposition that follows is an anticipation of treatment in Chapter 3. Economic dynamics is primed by innovation, that is, the introduction into prac-

tice of inventions that can be the result of discoveries sometimes made many decades before. But at the present time, invention and innovation are, for the most part, tightly linked to each other in the context of the research and development practiced by modern firms. Of course, many kinds of innovation may come to light. Here we limit ourselves to a main distinction which is of a great analytical importance: radical innovation, from time to time, gives rise to completely new products as well as to radically new organizational and technical processes and hence to an economic and behavioral revolution; incremental innovations, improve existing products and processes that accompany the diffusion of the main innovations. ${ }^{7}$ It may be useful to underline that here the new processes are intended both with reference to technical and organizational aspects (that Schumpeter considered separately); for its part, the concept of a new product can be extended to include the Schumpeterian discovery of new markets. The explanation of innovation must focus on entrepreneurship and uncertainty, as previously shown in the treatment of dynamic competition process.

Innovation implies a notion of endogenous time. This differs both from time intended as an absolute exogenous variable, in the Kantian sense, and a relative variable in the sense of Einstein/Minkowski or thermodynamics (Prigogine, Georgescu-Roegen). Our endogenous time also differs from the Darwinian evolutionary perspective, this being an extremely slow natural mutation-selection process that does not show true leaps. The endogeneity of time in this analysis may be interpreted as stating that a new time starts when radical innovation appears. In the formalized and simulated model of Chapter 3, endogenous time will appear in the diffusion, through a logistic (or a Gompertz function) of radical product innovation, while in the diffusion of radical process innova-tion, endogenous time is implicit in the 'memory' of a Gamma distribution. The leaps caused by the apparition of innovations are formalized through switch functions.

As we noted in the subsections on dynamic competition and uncertainty, the entrepreneur's search for profit is at the heart of the innovative process. In particular, the push to innovate depends on the persistence of negative profit rates (innovate or perish), ${ }^{8}$ a low degree of radical uncertainty, the excess of entrepreneurship and the improvements stimulated by radical innovations; while product innovations are also stimulated by the difficulty of selling the existing products and the inequalities in income distribution. This will be formalized in Chapter 3. An important consequence of innovation, that is, breaking the existing equilibrium, is a push of radical uncertainty (to be distinguished by probabilistic certainty) that reinforces the entrepreneur's role. The development process is obliged to be an entrepreneurial one, both because it cannot do without innovation, its prime mover, and because it is obscured by the clouds of radical uncertainty. 
The interaction between innovation, uncertainty and entrepreneurship, in the context of the dynamic competition process previously discussed, generates a cyclical behavior promoted by the advent of new processes and new products. The cycle can be described as follows.

Let us start from a cyclical phase characterized by the stagnation of production, low innovation and low uncertainty (since there is no variability of expectations and opinions, they are diffusely and firmly negative), and hence a high excess of entrepreneurship (depression). This situation and the associated decline in profit rates will favor the use of radical innovations (innovate or perish) and hence the beginning of a recovery of production and profit rates. During the depression, innovation operates both in the field of process and product; it privileges existing industries which can benefit from a more immediate push. But recovery sees a fall in the main process innovations in existing industries, while the advent of product innovation persists. The diffusion of radical innovation and the advent of incremental innovations following the radical ones will favor expansion, thus opening the door to a phase of prosperity. The associated economic expansion markedly reduces the excess of entrepreneurship and innovation, leading toward a break point: recession. The consequent decrease in profit rates opens the door to a new phase of depression and the excess of entrepreneurship. Such a mechanism is at the heart of the so called long waves. ${ }^{9}$

This cyclical motion is twofold, as distinguished by the adoption of new productive forms and techniques, with the associated increases in productivity, and the advent of new products, mainly new consumer goods. In parallel, the advent of new capital goods will strengthen the achievement of productivity increases.

There exists an important nexus between both kinds of innovations: precisely, the advent of new products is pushed and made necessary by the increase in productivity due to process innovation; in fact, sooner or later, the demand for the existing goods will become insufficient to absorb the productivity increase. Pyka and Saviotti ${ }^{10}$ have pointed out this aspect. But their modeling is partial since it does not contemplate process innovations, notwithstanding these are indispensable to cause, through the productivity rise and the deficiency in the demand for existing goods, product innovation.

The advent of a new product and its diffusion according to a sigmoid function (the logistic or Gompertz curve) explain the product cycle that goes through the following phases: introduction of the new product in the market; acceleration of its demand; maturity, when demand stops growth; decline, when consumers' preferences for the product start to decrease. New products cause the increase of uncertainty in the existing sectors of consumer and capital goods. This interferes with the process innovations that precede, in some sense, the cycle of consumer products and, as previously seen, are promoted by the search for productivity increases.

The formal model expressed in Chapter 3 will provide a more stringent descrip-tion of the development process in the modern dynamic economies; a main pur-pose is to give some substantial push to the research in this field afflicted by too many misunderstandings. 
Theoretical frame

1

3

\section{A critical review}

\subsubsection{Some equivocations and omissions of general economics}

Economics has usually disregarded uncertainty. In particular, mainstream economics has grown as a theory of perfect knowledge. Coherently with this assumption, it has taken care to include only casual events expressing probabilistic certainty (i.e. well-specified probability distributions), while it does not consider uncertainty, entrepreneurship, innovation or, in other words, dynamic competition.

F.H. Knight was the first economist that insisted on the notion of uncertainty; with this term, he intended to imply chance rather than a known probability distribu-tion and, therefore, something uninsurable and for which cost cannot be provided.

This author insistently underlines that both profit and entrepreneurial function are the result of immeasurable uncertainty. That immeasurability is the leitmotif of his main work. He writes: "We restrict the use of the term 'uncertainty' to non quantitative cases. It is this 'effective' uncertainty, not risk, as we said, that constitutes the base for a correct theory of profit and gives account of the divergences between effective and theoretical competition. ... The essential principle of perfect competition that warrants, in principle, the results toward which effective competition 'tends', is the absence of uncertainty (in the true sense of non measurable uncertainty)". 11

We have seen that one main task of economics and businessmen is to get a measure (and explanation) of the degree of uncertainty of expectations. Moreover, we shall see in Chapter 6 that it is generally quite easy to measure uncertainty by industry and size of firms. ${ }^{12}$ Knight insists on the uniqueness of the events representing uncertainty. As we said, a lot of events that are normally insured are unique. A theft and a fire are unique events; their grouping by homogeneous classes is always rather forced. A road accident is unique as connected to the ability of the driver. Notwithstanding, those events are, as a rule, insured.

Knight writes in a note: "If in a particular case uncertainty is measurable, it can be substantially eliminated by grouping and consolidating a number of cases large enough to warrant certainty with respect to the all group". ${ }^{13}$ But we have previously seen that firms' results are not insured because the entrepreneur must be charged with the final responsibility of decision making to be induced to decide accurately. It seems important to insist on the falsity of Knight's postulate of immeasurability of uncertainty since it has caused great equivocations in economic thought, mainly a diffused hostility to (and a denial of) the possibility of explaining radical uncertainty, as we shall see later more in detail. For this point to be clarified, it must be connected to the notion of dynamic competition that, as we know, has uncertainty at center stage. More precisely, it is necessary to assert that it is not the immeasurability of uncertainty that causes dynamic competition and prevents insurance; the opposite is true: dynamic competition is the central feature of the economic process and the engine of economic growth 
and development, which stimulates uncertainty and makes senseless the insurance of firms' results.

Knight does not discuss the phenomenon of dynamic competition. At the basis of this omission there is a methodological misunderstanding, which is surprising in an author who dedicated great attention to method. Precisely, he confuses abstrac-tion, necessary to any theoretical development, with the method of abstract ratio-nality typical of logical-formal sciences that use postulates abstracted from reality; as such, they may upset the content of reality and lead to absurd formulations. Knight treats the theory of perfect knowledge (pure economics) without seeing that the idea of perfect knowledge implies a total distortion of reality. He introduces the notion of uncertainty only to mitigate the hypothesis of omniscience, while accu-rately ignoring the crucial phenomenon of dynamic competition as this is incon-sistent with the neoclassical approach. He states that the removal of the hypothesis of perfect knowledge implies only some insubstantial difference with respect to the neoclassical model of omniscience, and that such difference is expressed by the appearance of profit and losses. In sum, he limits himself to operating in a neoclassical context. His insistence on uncertainty represents an analytical advancement, but he refuses to see the irremediable fracture that uncertainty introduces with respect to neoclassical theory, mainly through the correlated phenomenon of dynamic competition. In effect, Knight's contribution is aimed at conferring a realistic look to neoclassical economics; in this way, he gets honors and avoids being considered a heretic. In effect, the ability to confer to their strongly unreal-istic approach a realistic look through some superficial manipulations is frequent among neoclassical students.

But reality cannot be suppressed. In fact, the phenomenon of uncertainty soon regained a first order position in economics with Keynes's macroeco-nomic analysis. Keynes concentrated on the links among uncertainty, money, long-term expectations and the connected volatility of investment and proved, on this basis, the phenomenon of the deficiency or excess of effective demand.

This led him to show the importance of managing demand in facing the ghost of uncertainty. The Second World War, which caused an enormous expansion of public expenditure, offered a precious opportunity to prove the usefulness of that theory and the associated economic policies.

Neoclassical students quickly integrated Keynes' teaching into their theories, in particular through the Hicksian IS-LM approach that accepts the idea of the nonneutrality of money. But at the micro level persisted the hegemony of the Walrasian theory of general equilibrium, with its pretension to represent the whole economic system rigorously and in all details. That persistence was strongly supported by Knight's teaching on uncertainty. Precisely, the exclusion from microeconomics of all the crucial features of modern economies represented by uncertainty, entrepreneurship and innovation was considered, on the basis of Knight's teaching, as an admissible simplification instead of an unacceptable distortion of reality. The confusion afflicting the method of social thought preserved by substantial 


\section{Theoretical frame}

criticism the majestic futility of the Walrasian theoretical approach. As far as we know, nobody has insisted with the due energy (as H. Ekstedt does ${ }^{14}$ ) on the basic mistake of general equilibrium models, that is, their inspiration to the method of abstract rationality, typical of logical-formal sciences: a method that leads to deduce, from purely nominalist postulates, some precise but useless and totally misleading consequences.

Neo-Ricardian criticism has limited itself to show the inconsistency of the neoclassical aggregate function of production, but this has not affected the substance of Walrasian microeconomics. Indeed, neo-Ricardian animosity against neoclassi-cal economics could not do more since it shared with the basic neoclassical methodology the method of abstract rationality, thus purging theory from uncertainty, entrepreneurship, innovation and hence dynamic competition, exactly like mainstream economics does. In effect, neo-Ricardian students have formalized nothing more than a simple linear system of prices by industry. This, together with its dual counterpart represented by output equations, gives a general equilibrium model specified at the industry level and hence is much more limited than neoclassical one. Its usefulness only concerns the statistical field.

The previous reference to general equilibrium models cannot omit a consideration on von Neumann's system, representing another largely appreciated applica-tion of the abstract rationality method. Von Neumann substitutes, to neoclassical unreal hypotheses, some others no less unreal (the absence of scarce resources, strictly subsistence wages, equal rates of growth by industry); on this basis and using the duality relation between output and prices, he calculates a vector of prices that, being associated to the highest possible rate of growth, are considered to be some best efficiency parameters.

All these general models of the economy share a basic lack: the absence of dynamic competition and the corresponding triad, that is, uncertainty, innovation and entrepreneurship. Their attraction only depends on them being some brilliant mathematical toys. The fact that the models of perfect knowledge and stationary motion are coherent both with the prevailing method based on observation (and the connected hypothesis of repetition of events) and the method of abstract rationality has helped their acceptance. But both methods are inappropriate to social real-ity. The acceptance, by the main economic schools, of the previously mentioned senseless methodologies has impeded a fruitful debate and the necessary revision.

As is well known, the controversies between classical and neoclassical schools of thought were mainly centered on the problem of economic value and exploi-tation, and precisely the relations between prices and income distribution. But they did not achieve some important advancement in knowledge. What is worse, in such a field dominated by resentments and class conflicts, theoretical equivo-cations have caused dramatic consequences in practice. In particular, Marxism has associated with the fight against exploitation an extreme struggle against the entrepreneur and the market made plausible by the diffuse misconception of the phenomenon of uncertainty. Let us insist on this vicissitude constituting an impor-tant example of the absurdities that may be generated by human minds, even the sharpest ones, if deviated by methodological misunderstandings. 
The Marxist interpretation of social and historical process offers, notwithstanding some serious errors, ${ }^{15}$ a superb theoretical monument if confronted with the analytical poverty of the models sketched previously. Marx draws an analysis of capitalism magnifying the role of the market and the bour-geoisie in the building of the modern world. Such interpretation could have favored the development of a realistic and fecund economic theory, but, on the contrary, it has propitiated a real theoretical and operational disaster.

What are the reasons for that?

Marx, as an economist, was strongly influenced by classical thought, but much more by Ricardian than Smithian thought. In particular, Marx insisted on the valuelabor theory and hence indicated the market and entrepreneur as major causes of the troubles of society and exploitation. He concluded, therefore, that it is neces-sary to erase those institutions, as a condition of erasing exploitation. ${ }^{16}$ Marx's Das Kapital presents some traits of the superb Marxian interpretation of history, particularly in the second and third books where, as a consequence, the sterility of Ricardian influence becomes evident. He ignores the problem of the concrete organization of socialist systems that commit to the 'imagination of history', with his method swinging between naturalism and Hegel's teaching. But a social order deprived by the entrepreneur and the market is obliged to be a centralized social system, like 'real socialism', and hence only suitable to a stationary society, that is, antecedent to the stage of a modern dynamic society.

If Marx's economics had been more influenced by his historical analysis of capitalism than by the specifications of classical economists, probably he would have perceived the necessity, in modern dynamic societies, of the market and the entrepreneurial role (even if not necessarily in the form of the capitalist entrepreneur). All that should have appeared obvious to a student of historical process of Marx's stature. What is the reason for his misunderstandings on the matter? Certainly the arid Ricardo's teaching was not enough to confuse Marx.

The roots of his mistakes are in his method that blends Darwin's and Hegel's teachings, a mixture which is disastrous for the analysis of social reality mainly because both these authors associate real with rational, for different reasons, despite the importance of reducing, in social reality, the distance between real and rational. Marx considered society in Darwinian terms, that is, as result-ing from spontaneous evolution; at the same time, he considered, like Hegel, evolution to be able to proceed with rationality and evolve toward paradise on earth. This position forbade Marx to think in terms of the organization of social systems, that is, to investigate the institutional pillars requested by the general conditions of development typical of each historical age. ${ }^{17}$ In particular, this prevented him from understanding the importance of the entrepreneur and the institutional implications of uncertainty.

Mainstream economics, which has not been concerned with the MarxianDarwinian-Hegelian methodological wave, has largely used, as previously seen, the methods of abstract rationality and observation. Sometimes those methodologies operate simultaneously, as it is witnessed by the neo-Ricardian mixtures 


\section{Theoretical frame}

between Marxism and abstract rationalism, as well as by the mixture between naturalism and abstract rationality frequent in neoclassical thought.

In this theoretical landscape, the hypothesis of perfect knowledge and neoclassical economics could consolidate their hegemony without difficulty. As a consequence, even the controversy on market socialism that occurred between the two world wars was almost naturally based on the neoclassical theoretical paradigm. But the versatility of the neoclassical theoretical approach to incorporating both centralization, as in E. Barone's essay 'The ministry of production in collectivist state', and decentralization, as in Lange-Lerner-Taylor's decentralized socialism, where a simple rule for decision making substitutes for the entrepreneurial role and reveals the total unrealism of the approach. In fact, such a surprising possibility of generalization of the model derives from the fact that it ignores the crucial phenomena of entrepreneurship, uncertainty and innovation that make up the dynamic competition process, so it has nothing to do with reality. It is, therefore, not surprising that the debate on market socialism gave up in favor of the more realistic and useful Keynesian policies that made possible 'social democratic compromise'. But some posthumous resurrection of Barone's teaching took place in the 1960s and fed the Soviet Union's illusion to warrant the efficiency of its centralized economy simply using optimization models.

Finally, the total failure of real socialism made clear that its main vice consisted in the denial of some crucial necessities of modern dynamic economies, mainly the entrepreneur and the market; it became clear that it was improper and foolish to oppose the two in the name of social justice and that such opposition had given rise to a system of domination worse than the capitalist one. Unfortunately, the roots of wrong institutions and theories cannot be rapidly extirpated; dominating interests always act as fierce defenders of them.

The analyses on market forms, mainly perfect and monopolistic competition and monopoly, added no clarification on the omissions and misunderstand-ings discussed, in particular on the triad of uncertainty, entrepreneurship and innovation and the notion of dynamic competition. Those static analyses were based on the shape of supply-demand curves, with some exception in the studies of oligopoly. But it is easy to see that the earthquake caused by dynamic competition destroys the graphical bases of those theories on market forms. Dynamic competition implies, among other things, different prices for identical goods or, more precisely, that one source of profit is the skill to get advantageous prices. Besides, dynamic competition implies monopoly prices on new goods for the duration of the degree of the monopoly deriving from novelties.

Of course, price variations in a competitive market are caused by the disequilibria between supply and demand that drive to the coordination of both. But what factors cause the variation of the supply and demand curves? This is the true problem, and it is impossible to solve if the notion of dynamic competition and its components - uncertainty, entrepreneurship and innovation - are ignored. 
Post-Keynesian economics has extended Keynesian macroeconomics to indus-try level, thus driving economic theory to a higher degree of realism. But it does not consider microeconomic level and dynamic competition. The postKeynesian attempts to combine Keynes's, Marx's and Ricardo's teachings have caused some strong equivocations as a result of that omission.

The vivacious criticism addressed to the Walrasian notion of equilibrium ${ }^{18}$ has not offered some formulation able to remedy what is lacking in mainstream eco-nomics. Today, the fragmentation of economics in a variety of schools of thought that are unable to interact dominates the scene. Such a fragmented and confused theoretical context has prevented some important intuitions (that we shall con-sider in next paragraphs) to express useful synergies. In this theoretical landscape, neoclassical economics has been able to preserve the fascination deriving from its pretension to give a detailed and coherent representation of economic system. Various students of this school of thought have been clever to mask its unreal-ism, both at the macro level (e.g. through the models of endogenous growth and the IS-LM approach) and at the micro level (e.g. R. W. Clower's removal of the Walrasian hypothesis that transactions take place at equilibrium prices, which has stimulated a proliferation of studies on the so-called non-Walrasian equilibrium).

A development even more elegant and innocuous was provided by D. Patinkin by introducing money in the Walrasian model of general equilibrium, eliminating (but only apparently) the breakage between the monetary and real aspects without violating the idea of the neutrality of money. For their part, A. Wald, J. von Neumann and S. Zeuthen's contributions warranted the existence of economically meaning-ful solutions (non-negative output and prices) of equilibrium models. Finally, the theorists of rational expectations have managed to specify a surreptitious form of perfect knowledge in spite of radical uncertainty.

So, the neoclassical theory of omniscience, even if based on some absurd postulates and methods, has succeeded in reinforcing its hegemony through astute patchworks and with the help of the errors of opponents. It must be recognized, however, that among all schools of economic thought, the neoclassical one is distinguished by an admirable coherence. It has been a gymnasium of theoretical skills that may offer some important contribution, as soon as a methodology more appropriate to economic reality will be defined.

Now consider some formulations that may offer useful elements to build an economic theory that is able to bring on to the scene the great absent: dynamic competition, to be placed at the center stage of economics.

\subsubsection{Important advancement, but damaged by the missing link between the two faces of dynamic competition: adaptation and innovation}

As previously seen, Keynes provided, at the macro level, a precious deepening on the question of uncertainty. But, in other aspects, this phenomenon has been misunderstood or neglected, mainly due to the influence of Knight's analysis that held the consideration of uncertainty just as a refinement of the economics of perfect 


\section{Theoretical frame}

knowledge. Nevertheless, the problem of uncertainty was not long in returning to the fore and was subject to considerable deepening by G.L.S Shackle and P. Davidson. They insisted on crucial decisions and experiments, the world of order and inspiration, essential novelties and creative events, ergodicity and nonergo-dicity of processes, and subjective and objective uncertainty. But the attribution of decisive importance to the limits of knowledge and to trial and error processes is to the merit of neo-Austrian economics. The students of this school of thought have insistently underlined the links between entrepreneurship and uncertainty and the role of the market as a mechanism of information and discovery. In particular, they have insisted on representing economic competition as a result of entrepre-neurial activity directed at benefiting from the profit opportunities engendered by disequilibria, errors in decision making and the accidents which make economic life uneven. But neo-Austrians are responsible for some unilateral exaggerations, in particular Hayek, who based an apologia of spontaneous order on the limits of knowledge. He forgets that the condemnation of man to advance by trial and error implies that it is important to find ways of reducing as much as possible the number of errors, mainly through interventionism and the building of some organizational forms suitable to dynamic reality.

Probably the most enlightening teachings on uncertainty in neo-Austrian economics are due to I. Kirzner's work, mainly his development on 'market process'. He delineates a realistic and effective, even if incomplete, representation of the process of economic production and competition based on entrepreneurial alert-ness in taking profit from the opportunities offered by economic reality and the inevitable failures of forecasting. Unfortunately, Kirzner's analysis explains only one half of the process of dynamic competition, the one concerning adaptive entre-preneurial action directed to take advantage of the existing profit opportunities, which, as we saw, tends to erase profit. Kirzner neglects entrepreneurship directed at creating new profit opportunities through innovation. Indeed, he makes some attempts to remedy this lack by dividing entrepreneurial process in two compo-nents: entrepreneurial short-run competition and entrepreneurial discovery in the long run. But Kirzner limits himself to emphasizing the discovery of the existing opportunities, not the creation of new opportunities. ${ }^{19}$ He substantially ignores entrepreneurial action that engenders uncertainty and disequilibria, thus giving rise to arbitrage and market process. In sum, Kirzner disregards specifying radical innovation or, more generally, the dynamic aspect of the competition process, and hence 'endogenous' uncertainty.

A promising way to remedy this shortcoming and try to complete the representation of the dynamic competition process may consist of marrying Kirzner's market process to the Schumpeterian 'creative destruction'. Unfortunately, neo-Austrian and Schumpeterian teachings remain two separated branches of investigation, notwithstanding their strong complementarity. They make two opposite errors: the substantial absence of consideration of innovation, which is typical of neo-Austrians, and the substantial Schumpeterian absence of consideration of uncer-tainty. ${ }^{20} \mathrm{In}$ particular, Schumpeter does not attribute any importance to endogenous uncertainty that is produced by the economic system, notwithstanding that such 
endogeneity clearly springs off his notion of 'creative destruction'. This omission has determined the most surprising Schumpeterian error: the forecasting of the exhaustion of entrepreneurial function ${ }^{21}$ and the advent of socialism through big business. The error was repeated by J. K. Galbraith in The New Industrial State, which diagnosed the convergence between capitalism and socialism through the managerial firm. ${ }^{22}$ A superficial consideration of uncertainty would have been suf-ficient to show the authors the great obstacle that such a phenomenon poses to the centralization of decision making.

It is surprising that these two approaches have not been unified so as to supply a proper theoretical analysis of the great absent: dynamic competition. The missing ring that has prevented an effective and persuasive representation of a dynamic competition process, starting from the above neo-Austrian and Schumpeterian contributions, is represented by the exclusion from economics of a variable expressing the dimension of true or radical uncertainty and the explanation of this. In fact, the representation of the interaction between innovation and adaptation requires the expression of the endogenous variations of the level of uncertainty. Those variations cause: (a) the rise of entrepreneurial adaptive action when uncertainty (and disequilibria) grow together with the connected profit opportunities; and (b) the rise of innovation when uncertainty (and disequilibria) decrease due to adaptation process, since this decrease will make easier to innovate and will oblige to create profit opportunities through innovation. The explanation of the level of uncertainty is necessary, and it may allow for unification of neo-Austrian and Schumpeterian competition and, in this way, give a more complete and coherent formulation of the dynamic competition process and of the explanation of entrepreneurship. The mistaken Knight's postulate of the immeasurability of uncertainty, retained by economists with a surprising superficiality, and the connected diffusion of the idea that radical uncertainty cannot (and must not) be explained, have obstructed such a development. For better evidence of the persistent separation in economics of the two branches of dynamic competition, innovation and adaptation, it may be useful to quote the opinion that Kirzner expressed to us on the matter. ${ }^{23} \mathrm{He}$ said:

I realize, of course (and this was one of the purposes of my 'Creativity and/ or alertness' paper) that there are differences between the kinds of innovation Schumpeter had in mind, and the entrepreneurial 'discoveries' which I had insisted were the steps in the process by which Schumpeter's 'imitators' tend to bring about equilibrium. . . . I am reminded of Samuelson's imagery of the Schumpeterian process as similar to a violin string that has been plucked into vibration (by innovation), subsequently returning to its quiescent state (through the imitators) - except that you postulate that the very quiescence of this state stimulates further innovation, etc. . . . You imply that a reduction of uncertainty stimulates the rate of Schumpeterian innovation. I have not yet seen any rea-soning firmly leading to this conclusion. You seem to take it as obvious.

Yes, it simply is an expression of the search for profit and it is crucial for the specification of dynamic competition as given by the interaction of innovation 


\section{Theoretical frame}

and adaptation: when uncertainty and the adaptive opportunities of profit are low, there will be a stimulus to create opportunities of profit through innovation, which is easier to introduce in the presence of low uncertainty.

The persistent lack of consideration of dynamic competition is surprising. This seems to be a result of the absence of a method of social theory appropriate to the basic character of social reality. Such a lack condemns economics to offer con-fusing teachings. These darken even the most obvious and elementary problems through complicated and misleading formulations, with everybody claiming to be right in their own way. The next subsection will consider some equivocations that affect the strong opposition of heterodox economics to the economics of perfect knowledge.

\subsubsection{The exaggerated success of the notion of bounded rationality and the associated attack on optimization}

The aversion to the economics of perfect knowledge has grown with the accelera-tion of economic dynamics and hence the rise of uncertainty. In such an intellectual climate, the notion of 'bounded rationality' has come to light and has enjoyed rapid success due to its usefulness in opposing neoclassical perfect rationality. Unfortunately, that notion is undermined by numerous equivocations that need to be clarified.

In every field of life, man is forced to go ahead by trial and error. The understanding of nature is made difficult by the fact that such reality is not the work of man. On the contrary, the understanding of social reality is made difficult by the fact that it is a result of the interaction of a lot of human actions and creative events. But this difficulty is better expressed by the terms uncertainty or limited knowledge than by the expression 'bounded rationality'. In effect, human skills and rationality are always bound, by definition, to the limits of human knowledge.

An interesting definition may consist in the notion of 'cognitive rationality' that underlines the learning process connected to the use of human rationality. ${ }^{24}$ This process requires a measure of the degree of uncertainty to express the formation and use of entrepreneurial skills and to define the constraints of the cognitive process, as we shall soon see.

It must be recognized that the notion of bounded rationality has promoted some useful deepening of cognitive processes, in conjunction with M. Polanyi's research on 'tacit knowledge'. Unfortunately, that notion almost neglects the dynamic competition process although this represents the backbone of the economic process in the presence of limited knowledge. What is more surprising in the economics of bounded rationality is that it does not seem to understand the crucial importance of considering the level (and hence a measure) of the factor on which the lim-its of rationality depend, that is, the degree of radical uncertainty. This omission has implied the denial or the darkening of the possibility to explain uncertainty and suffocates the potentiality of this branch of heterodox economics; it prevents, as just seen with reference to neo-Austrian and Schumpeterian teachings, the 
formalization of the phenomenon of dynamic competition. It seems, therefore, sensible to ask to the growing number of students insisting on the notion of bounded rationality: What prevents you from seeing the importance of a measure and an explanation of the factor expressing the limitation of rationality, that is, the level of uncertainty? The economists who insist on bounded rationality disregard the question of the accuracy of expectations. But their negligence in producing a measure and an explanation of the volatility or variability of expectations is a surprising omission. This volatility is, at the same time, perfectly coherent with the notion of bounded rationality and gives a possible measure of the degree of uncertainty.

The galaxy of theories constituting the so-called heterodox economics testifies to an enormous analytical fragmentation that prevents the unification of efforts and results. One of the few aspects shared by heterodox students is the disputation with mainstream economics. But this convergence is afflicted by exaggerations and equivocations. In particular, the disputation has obscured, mainly through some abuse of the expression 'bounded rationality', the important fact that man is obliged, by his interests and competition, to use his rational skills, just like the opti-mization procedure maintains. It has been erroneously assumed that optimization presumes omniscience, an assumption that indeed would imply that Pontryagin's and Kantorovich's works are pointless. Kirzner wrote: "Where the circumstances of decision are believed to be certainly known to the decision-maker, we can 'pre-dict' what form that decision will take merely by identifying the optimum course of action relevant to the known circumstances. Now this 'mechanical' interpretation of decision-making would be entirely acceptable for a world of perfect knowledge and prediction". ${ }^{25}$ This assimilation of optimization to neoclassical economics is mistaken. Optimization does not require perfect knowledge; it is only a tool for decision making that often is more rational than others. Perhaps it would be much more enlightening to hinge the polemics against neoclassical thought on the notion of uncertainty than on that of bounded rationality.

The father of bounded rationality, H. Simon, opposed to optimization the principle of 'satisfying behavior'. But this principle is vague and can be variously interpreted, mainly with reference to the levels of aspiration and satisfaction.

All seems to show that the hostility against optimization is mainly due to two prejudices: (1) the habit of connecting the optimization principle to the hypothesis of omniscience, that is, perfect knowledge, thus forgetting that such a principle is simply a mathematical tool that does not need that hypothesis; and (2) the postulate of immeasurability and unexplainability of uncertainty, that is, the denial of the possibility of defining an endogenous variable expressing the degree of limitation of knowledge; this denial prevents the possibility of formalizing an optimization model including both uncertainty and the availability of entrepreneurial skills and hence the tension in the use of these. In fact, to define availability and tension, a measure and an explanation of the degree of uncertainty are needed.

Firms are forced by competition, more than other subjects, to act rationally as much as possible. This implies that firms' competition drives them to optimization; but this only means that optimization gives better solution than other procedures. In sum, an aprioristic refusal of optimization is not wise, this being able to supply a 


\section{Theoretical frame}

better rationality criterion than other decision-making tools. All that is quite simple and evident. The main reason obscuring this banal evidence is (let us repeat) the conviction that uncertainty is something impalpable and, as such, is inconsistent with optimization; this conviction leads to intend optimization as only referable to the absurd hypothesis of perfect information. The result is that, while neoclas-sical economists tend to strongly exaggerate human knowledge on the basis of the hypothesis of perfect knowledge, their opponents make an opposite exaggeration: the postulate of immeasurability and unexplainability of uncertainty that prevents obtaining important knowledge and urgent analytical development.

\subsubsection{An ambivalence afflicting the potentialities of economic and institutional evolutionary thought: entrepreneurial skills and decisional routines}

The notion of evolution strongly influences the modern economic thought and the analysis of institutions, in connection with the insistence on the limits of knowl-edge or radical uncertainty. Unfortunately, the use by economics of the evolution-ary metaphor is afflicted by ambivalence. From the one side, Hayek and neo-Austrians underline the limitation of knowledge as a support to the idea that economic processes and the evolution of institutions are the result of spontane-ous behavior; as a consequence, they strongly dislike the organizational view of method, to which they oppose 'spontaneous order', and hence they are inclined to neglect the problem of the firm. On the contrary, institutional students emphasize organization and utilize the notion of uncertainty to explain institutions and, hence, the firm.

To understand these aspects, some consideration of Nelson and Winter's contribution may be useful. ${ }^{26}$ The development of these authors is mainly based on Schumpeterian work; this has prevented, for the reasons indicated previously, the adequate representation of the dynamic competition process, which should be at the center stage of heterodox economics. Nelson and Winter's analysis shows, however, some differences with respect to Schumpeter that must be noted.

Evolutionary economics does not neglect uncertainty, but it incorporates it in the notion of bounded rationality and considers unquestionable the postulate of immeasurability of (and the impossibility to explain) uncertainty. Unfortunately, this postulate, and the consequent setting aside of the optimization principle, engender a vague theoretic atmosphere. Evolutionary economics' main remedy to that vagueness is the notion of 'decisional routines', which are intended to provide a solid conceptual basis to decision making; some evolutionary econo-mists have assimilated decisional routines to biological genes. Here it appears again: the methodological inappropriateness of the postulate of immeasurability of uncertainty. In fact, it is mainly due to that postulate that this branch of economics separates entrepreneurial function from uncertainty in the context of the notion of routine. But the various developments on routines do not provide stringent empiri-

cal and conceptual formulations; ${ }^{27}$ they presume some very simple decisional rules emphasizing the automaticity of decision making, but this is inconsistent with the entrepreneurial role and hence does not allow the explanation of entrepreneurship. 


\section{Innovation, uncertainty, entrepreneurship}

25

Nelson and Winter intend routines as organizational memories, as forms of tacit knowledge, in M. Polanyi's sense. They consider routines to be the most important storage of organizational knowledge. The firm's behavior should be explained through the used routines, and it should be expected that in the future the firm will behave similarly to the past, the change in routines being obstructed by the consequent fracture of equilibrium and organizational compromises. However, innovation in the rules of decision making is considered possible and important. But entrepreneurship is inconceivable and inexplicable if separated by radical uncertainty. It must be stressed that the notion of routine has nothing to do with entrepreneurship. Entrepreneurship is mainly a skill to meet uncertainty, while routine means repetition and hence implies bureaucratic skills. Heterodox analy-ses have dedicated a good deal of work to organizational skills, but they say very little on entrepreneurship. Entrepreneurial decisions, at least the most important of them, do not follow any precise rules. The various branches of heterodox econom-ics, in trying to reduce, through the notion of routine, the indeterminacy deriving from the notion of bounded rationality and from the postulate of immeasurability of uncertainty, forget the flexibility and versatility of entrepreneurship. M. Egidi and A. Narduzzo have empirically shown that the use of routines that were effec-tive in the past may cause systematic decisional errors. ${ }^{28}$ It is our opinion that the analytical indeterminacy of entrepreneurial decisions cannot be faced through the reference to some precise decisional rules; it requires ventures in uncertainty, where entrepreneurship acts. More precisely, it is important to define some criteria that allow for measuring and explaining the level of radical uncertainty and its variations, so as to provide both a more solid basis to decision making and some analytical developments on the formation and the use of entrepreneurial skills; on innovation, disequilibria and adaptation, in brief, on the dynamic competition process.

It must be noted, however, that the growing attention dedicated to uncertainty and to the limits of knowledge has stimulated, among evolutionary students and in opposition to spontaneous evolutionism, some interesting developments on organization, mainly in the field of the firm. We saw that uncertainty requires some peculiar institutional forms. In this light, it is relevant that the firm has been indicated, by the economists of 'transaction costs', as an organizational necessity since it reduces uncertainty due to those costs by introducing hierarchical com-mand mechanisms to the market. This theory is important, but it explains less than supposed, mainly on the firm dimension. In fact, the increase in the sizes of firms reduces the market transactions and hence the uncertainty caused by the incompleteness of corresponding contracts. Moreover, the bureaucratization of decision making in large firms reduces the capabilities to face the unknown. Of course, it is possible to remedy that inconvenience through decentralized organizational forms, but this possibility is opposed by the centralization of last instance responsibility. Besides, the strategies devoted to reducing uncertainty are weakened and opposed by the fact that entrepreneurial innovation engenders uncertainty.

The dimensions of the firm seem mainly influenced by the quality and quantity of available entrepreneurial skills and uncertainty, which determine the potentialities 
of those skills and their demand. In conclusion, the best way to treat radical or true uncertainty seems to be introducing explicitly it into the models for decision making so as to estimate its impact on strategic choices and some other important variables, rather than setting uncertainty aside on the basis of the hypothesis that it cannot be measured and explained.

Neoclassical students, with the purpose to improve the realism of their theories, have suggested introducing into optimization models the skill to face uncertainty. But this idea and the others concerning uncertainty need a variable expressing their levels, a possibility denied by the postulate of immea-surability (and nonexplanation) of radical uncertainty. Such a postulate seems to represent a principal obstacle to the building of an economic theory that is able to conjugate uncertainty, entrepreneurship and innovation and an obstacle to defining the way uncertainty influences (and is influenced by) entrepreneurship and innova-tion. The representation of the dynamic competition process and economic devel-opment requires the abolition of that postulate. There exists a tight link between entrepreneurial skill and uncertainty; in fact, in the absence of radical uncertainty, there would be no need for (and no formation of) entrepreneurship. As the notion of dynamic competition shows, the entrepreneur meets uncertainty, but also gener-ates uncertainty, through innovation.

Entrepreneurial capabilities are mainly a result of tacit knowledge (learning by doing, by watching and by using) and innate skills. These capabilities vary, there-fore, with experience. It follows that, even if one main characteristic of them is versatility, the operational experience confers to skills some degree of specializa-tion that restricts their field of competence.

Darwinian evolution cannot be referred to the interpretation of economic and social events. Such interpretation needs an organizational view to may consider the growing pace of economic and social change, while the extremely low change concerning the advent of new animal species allows, in biology, the use of the observational view. However, after the elimination of the misunderstandings considered in this section, the combination of institutional and evolutionary thought seems to offer a fecund methodological perspective for the study of social events. In fact, the institutional character of human societies decisively influence the pace of their evolutionary change and, for its part, the sedimentation of changes determines the necessity to edify, in the context of changing general conditions of development, of new institutions. So that, the importance of the institutional aspect side by side with the evolutionary motion appears evident and concerns also ethical aspect. In this regard, see chapter 2 section 2 on the role of ontological imperatives (often of ethical content) in pushing the evolutionary motion, and the role of functional imperatives in providing the institutions required by the changing general conditions of development. 


\subsubsection{Some limitations of econometrics and the definition of a measure of uncertainty}

In the last 50 years, sophisticated econometric methods have been developed, sometimes using some impressing mathematical techniques. A dominating convic-tion is that those methodologies are able to express some universally valid results. But the opposite is true.

In general, econometric estimations may be referred only to the past or, more precisely, to the considered observation period, not to the future. Some limited and cautious application to the future may be justified if there exist reasons to think that the considered phenomena are long lasting. But how does one prove this property of phenomena? An important way to do that may be to determine if they result from the existing general conditions of development. In this case, the high durability characterizing those conditions should warrant a parallel durability of the corresponding phenomena, these being an expression of those conditions of development that impose corresponding organizational structures for reasons of coherence and efficiency. Well, dynamic competition and its con stituent triad, that is, uncertainty, entrepreneurship and innovation, are basic durable aspects of modern dynamic economies. Even if the parameters resulting from the connected estimation may vary over time, those variations do not 
destroy the explanatory power of the estimated relations. But statistical data do not exist on these variables. This prevents us from making econometric estimations about them, as we shall see in the modeling outlined in Chapters 3 and 4 , where we have been obliged to restrict our analysis to simulations, since econometric estimations are prevented by the absence of statistical data on entrepreneurship, innovation and radical uncertainty. In particular, the dominant conviction as to the impossibility of providing a measure of radical uncertainty completely voids the question of the availability of data on this variable. But we have seen in Section 1.2 that the idea of nonmeasurableness of radical uncertainty is completely wrong.

To get ahold of the ghost of uncertainty, more than one quantitative indicator of this variable must be defined. As we shall see extensively in Chapter 6, we have specified and tested three criteria of measure. One has been derived from the European Union - Institute of Studies for Economic Analysis (EU-ISAE) surveys on business tendency and consists of the measure of the variability over time of the answers, that is, the volatility of the opinions (concerning the expectations on delivery orders, production, prices and cost of financing and liquidity assets) of each firm of the utilized sample. Another indicator has been provided through the inclusion of an opposite question on uncertainty in an ISAE survey for some recent quarterlies starting from April 2004; another measure of uncertainty could be derived from the deviations between expectations and results in the EU-ISAE surveys. A peculiar indicator of uncertainty may be given by the standard deviation of profit rates across firms; in fact, in the absence of uncertainty and of institutional monopolies, profit (and hence its standard deviation across firms) would be zero. Differentials in capabilities and the associated profits are conceivable only in the presence of limits to knowledge (true uncertainty); for this reason, the variance of profit rates across firms may be intended as an expression of the limits of knowledge and hence of uncertainty.

Some other indicators of uncertainty may be the specification of a minimummaximum range of expectations, with the distance between the minimum and maximum expectation that may be considered as an expression of the degree of uncertainty. Also the standard deviation (i.e. the distribution about the means) of foresights may be interpreted as a measure of uncertainty.

As is well known, uncertainty displays some very important effects on irre vocable choices and hence on investment. In order to improve the explanation of investment, some studies ${ }^{29}$ have proposed specifying the laws (or costs) of learning in getting information on decisions that are postponed, so that to may estimate the convenience of postponing the decisions to invest. But the hypotheses concern-ing those laws and costs are, in general, scarcely realistic. Uncertainty discour-ages investment in a different and more direct way. Precisely, high uncertainty suggests the postponement of investment for at least two reasons: (1) waiting for a more serene atmosphere and (2) increase in the use of entrepreneurial skills in ordinary activities, requested by the increase in turbulences. This makes the degree of uncertainty an important explanatory variable of invest-ment. Unfortunately, econometric estimations using some proper indicators of the degree of uncertainty are rare. We dedicate much attention to uncertainty in Chapter 6. 


\section{Theoretical frame}

\subsection{Conclusion}

This chapter points out that one main deficiency of economic thought is the lack of consideration of dynamic competition processes that are hinged upon entrepreneurship, innovation and uncertainty. This aspect is completely neglected by mainstream economics. Only three schools of thought have dedicated some useful considerations to the phenomenon. Two of them, neo-Austrian and Schumpeterian, are strongly complementary: the first emphasizes uncertainty and entrepreneur-ship, but almost ignores innovation, while the second emphasizes the entrepreneur-ial role and innovation but neglects uncertainty. These omissions prevent the two schools of thought adequately developing the notion of dynamic competition. We have seen that the assumption of immeasurability of uncertainty and the associ-ated denial of its explanation, which are explicit in neo-Austrians (Kirzner's 'fog of uncertainty') and implicit in Schumpeter, prevents an adequate treatment of the formation and use of entrepreneurship and the innovation-adaptation process, hence economic development. Moreover, the assumption of immeasurability of uncertainty and the emphasis on the limits of knowledge have diffused the mis-taken conviction that the maximization principle is only applicable to the neoclas-sical economics of perfect knowledge.

The equivocations we are stressing are shared by heterodox economics, which insists on the notion of 'bounded rationality'. Indeed, this notion has amplified the misunderstandings provoked by the assumption of immeasurability and unex-planability of uncertainty. This is clearly evident in evolutionary economics, the third school of thought that embodies some aspects of dynamic competition. Such a school (following Schumpeterian thought) has, at its heart, innovation and emphasizes the limits of knowledge as expressed by the notion of bounded rationality. Unfortunately, this notion is rather ambiguous; human rationality is always bounded, but this does not deny that decision making must make an effort to use reason at its best, as the optimization approach attempts to do. Nevertheless, heterodox economics rejects optimization.

Evolutionary economics tries to remedy some theoretical vacuity arising from the limitations mentioned through the notion of 'decisional routines'. But this notion is far from clear. In particular, it refers to a kind of skill that has nothing to do with entrepreneurship since it postulates repetitive, bureaucratic decision making, while a main characteristic of entrepreneurial skills is versatility and flex-ibility. Evolutionary economics is also afflicted by various misunderstandings on dynamic competition, even if for theoretical reasons it is partly different from neo-Austrian and Schumpeterian thought.

In sum, the crucial phenomenon represented by dynamic competition, when is not disregarded altogether, is treated in a partial and misleading way without properly considering entrepreneurship, uncertainty and innovation. This chapter has tried to remedy these drawbacks. 


\section{Notes}

1 It has been fully developed in A. Fusari, Methodological Misconceptions in the Social Sciences (Springer, 2014).

2 See A. Fusari (1996a).

3 With the exception of its exogenous part depending, for instance, on natural events.

4 When a better technology is invented, the old production processes must adapt to the prices imposed by the new one. At this point, if those prices no longer enable old producers to amortize the costs of their plants and the latter cannot be fully depreciated, the businesses with obsolete technology will have losses. There will also be losses if the new prices only permit, for the remaining physical life of the equipment, amortization rates lower than would be necessary to fully recoup the investment.

5 Thus their analysis is not particularly suitable for explaining the efficiency of choices made in different social and institutional contexts.

6 If depreciation was systematically overestimated (and thus overcharged), this would introduce an arbitrary element of extra profit. If, on the other hand, depreciation was systematically underestimated, it would introduce a systematic factor of loss. But this cannot happen, due to competition.

7 The distinction between radical and incremental innovations, frequent in economics, is for the most part not rigorous. It needs a precise expression of the degree of importance of innovations.

The degree of importance of a new consumer product can be represented by the quantity of its production (the conquered market as expressed by the superior asymptote of the logistic) at the end of the diffusion period and by the substitution and comple-mentary effects of the new product on the existing consumer goods.

The degree of importance of a capital product innovation may be expressed by the superior asymptote of the logistic and the parameters indicating the stimulating effects of the new capital products on process innovation.

Finally, the degree of importance of process innovations is represented by the leap in productivity that they cause.

8 See Mensch (1979).

9 See Fusari and Reati (2013).

10 See Pyka and Saviotti (2004).

11 See F. H. Knight (1950), pp. 18 and 19.

12 See A. Fusari (2006).

13 See F. H. Knight (1950), p. 165.

14 See Ekstedt and Fusari (2010).

15 See A. Fusari (1996a).

16 The generic attribution of production to labor is pointless since production largely results from human creativity. Another thing is the statement that the fruits of the natu-ral lottery of talents must be for the benefit of the whole society, but paying attention to not obstruct creativeness, as we shall see in Chapter 11.

17 See (Fusari 2014).

18 Kaldor wrote: "In effect, the theory of (general) equilibrium has reached a stage of development characterized by the fact that pure theorists have succeeded (even if unconsciously) to prove the impossibility that the implications of that theory are empiri-cally true" (cited in D'Antonio 1975, p. 77).

19 Kirzner writes: "To understand development it is necessary to understand the entrepre-neurial process whereby opportunities that where hitherto existent but unseen become opportunities seen and exploited" (Kirzner 1985, p. 74).

20 Schumpeter very much admired the Walrasian model of general equilibrium: "Magna Charta of economics ... enormous research program ... the base of the best work of our time". See Schumpeter (1972), pp. 482 and 556. 


\section{Theoretical frame}

21 Schumpeter writes: "The giant industrial unit, perfectly bureaucratised . . . supplants the entrepreneur" (Schumpeter 1977, p. 130).

22 Galbraith says: "Nothing is today more interesting than to see that the entity previously known as capitalist firm and that previously known as socialist firm begin to resemble under the oligarchic direction of technostructure" (Galbraith 1968, p. 343).

23 Private correspondence dated 7 December 2006.

24 See Morroni (2005).

25 See Kirzner (1973), pp. 33 and 37.

26 See Nelson and Winter (1982).

27 See Becker (2001).

28 See Egidi and Narduzzo (1997).

29 See Pindyck (1991) and Ulph and Ulph (1994).

\section{References}

Alchian, A. A. \& Demsetz, H. (1972), Production, information costs, and economic organization, American Economic Review, vol. 62, pp. 777-795.

Barone, E. (1971), Il ministro della produzione nello stato collettivista, in G. Lunghini (a cura di), Valore, prezzi ed equilibrio generale, Il Mulino, Bologna, p. 76.

Becker, M. C. (2001), Empirical research on routines: The state of the art and its integra-tion into the routines debate, EAEPE Conference of Siena, November 8-11.

Berardi, G. G. (1969), Saggi sullo sviluppo economico e sociale dei paesi arretrati, Giuffrè, Milan.

Calcagnini, G. \& Saltari, E. (1997), Un'analisi del principio dell'acceleratore in condizioni di incertezza, Rassegna dei Lavori dell'ISCO, vol. 1, pp. 183-212.

Cantner, U., Hanusch, H. \& Pyka, A. (1998), Routinized innovations: Dynamic capabilities in a simulation study, in O. Eliasson \& C. Green (eds), The microfoundations of eco-nomic growth, University of Michigan Press, Ann Arbor, pp. 131-155.

Coase, H. (1937), The nature of the firm, Economica, vol. 4, pp. 386-405.

D’Antonio, M. (a cura di). (1975), La crisi post-keynesiana, Boringhieri, Torino.

Davidson, P. (1994), Post Keynesian macroeconomic theory, Edward Elgar,

Aldershot.

Dosi, G., Nelson, R. R. \& Winter, S. G. (2000), Introduction: The nature and dynamics of organizational capabilities, Oxford University Press, Oxford.

Dosi, G. \& Teece, D. J. (1998), Organizational competences and the boundaries of the firm, in R. A. Arena \& C. Longhi (eds), Market and organization, Springer, Berlin, pp. 281-302.

Egidi, M. \& Narduzzo, A. (1997), The emergence of path-dependent behaviors in cooperative contexts, International Journal of Industrial Organization, vol. 15, no. 6, pp. 677-709

Ekstedt, H. (2006), Homo economicus versus homo politicus: A note on rationality, EAEPE International Conference of Istanbul.

Ekstedt, H. \& Fusari, A. (2010), Economic Theory and Social Change, Routledge, London, New York.

Fusari, A. (1996a), Sviluppo e organizzazione dei sistemi sociali. Una teoria interpretativa dei processi storici. Sociologia, vol. 1, no. 1, pp. 125-178. 
Fusari, A. (1996b), Paths of economic development: Modelling factors of endogenous growth, International Journal of Social Economics, vol. 23, no. 10/11, pp. 164-191.

Fusari, A. (2004), A reconsideration on the method of economic and social sciences: Procedure, rules, classifications, International Journal of Social Economics, vol. 31, no. $5 / 6$, pp. 501-535.

Fusari, A. (2005a), Toward a non-capitalist market system: Practical suggestions for curing the ills of our economic system, American Review of Political Economy, vol. 3, no. 1, pp. 85-125. www.arpejournal.com. 
Fusari, A. (2005b), A model of the innovation-adaptation mechanism driving economic dynam-ics: A micro representation, Journal of Evolutionary Economics, vol. 15, no. 3, pp. 297-333.

Fusari, A. (2006), Radical uncertainty indicators: Quantitative specifications and applications, 28th CIRET Conference, Rome, on "Cyclical Indicators and Economic Policy Decisions".

Fusari A. (2014), Methodological Misconceptions in the Social Sciences. Rethinking social thought and social processes, Springer, Dordrecht, Heidelberg, New York, London.

Fusari, A. \& Reati, A. (2013), Endogenizing technical change: Uncertainty, profits, entrepreneurship. A long-term view of sectoral dynamics, Structural Change and Economic Dynamics (SCED), vol. 24, 76-100.

Galbraith, J. K. (1968), Il nuovo stato industriale, Einaudi, Torino.

Grebel, T., Hanusch, H. \& Pyka, A. (2001), An evolutionary approach to the theory of entrepreneurship, EAEPE Conference of Siena.

Hanusch, H. \& Pyka, A. (2007), Elgar companion to neo-schumpeterian economics, E. Elgar, Cheltenham.

Hodgson, G. M. (1999), Evolution and institutions, Edward Elgar Cheltenham, UK and Northampton, MA.

Kirzner, I. M. (1973), Competition and entrepreneurship, The University of Chicago Press, Chicago and London.

Kirzner, I. M. (1985), Discovery and the capitalist process, The University of Chicago Press, Chicago and London.

Knight, F. H. (1950), Risk, uncertainty and profit, La Nuova Italia, Firenze.

Lange, O. \& Taylor, F. M. (1938), On the economic theory of socialism, edited by B. Lippincot, University of Minnesota Press, Minneapolis.

Langlois, R. N. \& Foss, N. J. (1999), Capabilities and governance: The rebirth of production in the theory of economic organization, Kyklos, vol. 52, pp. 201-218.

Lerner, A. P. (1938), Theory and practice in socialist economics, The Review of Economic Studies, vol. 6, no. 1, pp. 71-77.

Mensch, G. (1979), Stalemate in Technology. Innovations Overcome the Depression, Ballinger, Cambridge, MA.

Mises von, L. (1946), Economic calculus in the socialist state, in F. A. Hayek (ed), Collectivist Economic Planning, University of Chicago Press, Chicago.

Morroni, M. (2005), Knowledge, scale and transactions in the theory of the firm, Cambridge University Press, Cambridge.

Nelson, R. R. \& Winter, S. G. (1982), An evolutionary theory of economic change, The Belknap Press of Harvard University Press, Cambridge, MA.

Neumann von, J. (1952), Un modello di equilibrio economico generale, L'Industria, Il Mulino, Bologna.

Odagiri, H. (1994), Growth through competition, competition through growth, Clarendon Press, Oxford. 
Pasinetti, L. L. (1981), Structural change and economic growth: A theoretical essay on the dynamics of the wealth of nations, Cambridge University Press, Cambridge.

Pindyck, R. S. (1991), Irreversibility, uncertainty, and investment, Journal of Economic Literature, vol. XXIX, no. 3, pp. 1110-1148.

Polanyi, M. (1966), The tacit dimension, Doubleday, Garden City, NY.

Pyka, A. \& Saviotti, P. P. (2004), Economic development by the creation of new sector, Journal of Evolutionary Economics, vol. 14, no. 1, February, pp. 1-35.

Reati, A. (1998), Technological revolutions in Pasinetti's model of structural change, productivity and prices, Structural Change and Economic Dynamics, vol. 9, no. 2, pp. 245-262.

Richardson, G. B. (1972), The organization of industry, The Economic Journal, vol. 82, pp. 883-896. 


\section{Theoretical frame}

Saviotti, P. P. (1996), Technological evolution, variety and the economy, E. Elgar, Cheltenham .

Saviotti, P. P. (2001), Variety, growth and demand, Journal of Evolutionary Economics, vol. 11, no. 1, pp. 119-142.

Saviotti, P. P. \& Metcalfe, J. S. (Eds.). (1991), Evolutionary theories of economic and tech-nological change, Harwood Academic Publishers, Reading.

Schumpeter, J. A. (1934), The theory of economic development, Harvard University Press, Cambridge, MA.

Schumpeter, J. A. (1954), Capitalism, socialism and democracy, Allin and Unwin, London, Italian edition by Etas Libri, Milan, 1977.

Schumpeter, J. A. (1972), History of economic analysis, Boringhieri, Torino. Scott, M. F. (1989), A new view of economic growth, Clarendon Press, Oxford.

Shackle, G. L. S. (1990), Time, expectations and uncertainty in economics: Selected essays, edited by J. L. Ford, Edward Elgar, Aldershot.

Stoneman, P. (2007), Technological diffusion: Aspects of self-propagation as a neoSchum-peterian characteristic, in Hansuch \& Pyka (eds), pp. 377-387.

Ulph, A. \& Ulph, D. (1994), The irreversibility effect revisited, Department of Economics, University of Southampton, Southampton.

Walras, L. (1926), Elements d'économie politique pure ou theorie de la richesse sociale, R. Penchon et R. Durand-Auxia, Parigi.

Williamson, O. E. (1981), The modern corporation: Origins, evolution, attributes, Journal of Economic Literature, vol. XIX, December, pp. 1537-1568.

Wymer, C. R. WYSEA package for system estimation. Mimeograph. Wymer, C. R. \& Knight, M. D. (1978), A Macroeconomic Model of the United Kingdom, International Monetary Fund Staff Papers, vol. 25, no. 4, pp. 742-778.

\section{Abstract of Chapter 2}

In this chapter we extend and deepen the critical content of the previous chapter, making specific reference to those particular doctrines that have fanned the flames of heated disputes between the so-called mainstream and heterodox schools of economics. We first bring to light some considerations on the method of social science, and explain why methodological misunderstandings have damaged the explanatory potential of various rival theories. In the last part of the chapter we advance some ideas as to the best ways of overcoming those misconceptions that are widespread in current economics, thereby advancing the construction of an alternative theoretical edifice built upon more scientific ground.

\section{Abstract of Chapter 3}

This chapter specifies a model able to represent at the maximum level of sectoral disaggregation (a sector for each good) the production and accumulation process typical of modern dynamic economies. The mechanism driving the evolutionary motion of the economy is based on the interactions 
between innovation, uncertainty and entrepreneurship. The relationship between the proposed mechanism, the connected cycles, and the explanation for each one of those variables, which are often treated as exogenous, merits great attention. We insist that the innovation-adaptation (or structural organization) process expresses the phenomenon of dynamic competition, and we point out that it also allows some instructive description of social and historic processes. In this matter the current economic theories show a real and, let us say, inevitable impotence.

\section{Abstract of Chapter 4}

In this chapter the analysis is extended to the micro level, thereby providing for a more complete representation of the economic process as a whole, and bringing to light in particular entrepreneurial action. This chapter brings to light the great gulf between our construction and that of the Walrasian approach, highlighting the explanatory poverty of the latter. Initially, we show a model characterized only by adaptation, which as such suggests a suicide of entrepreneurship. Then we consider the complete model, in which the entrepreneur practices innovation as well as adaptation. The complete model thus expresses the whole substance of the phenomenon of dynamic competition.

\section{Abstract of Chapter 5}

In order to provide a more complete analysis of the micro level, we pay attention in this chapter to the question of the firm considered in close connection with the phenomenon of radical uncertainty. Some of the main issues in the dense debate over the firm are set out and criticized, most notably the controversy between those who, distrusting organization and favoring spontaneous motion, tend to pass over the significance of the firm, and those concerned with the evolution of institutions, who see the firm as a crucial economic institution.

Some clarification of the optimization approach with regard to the firm's decision making is also set out. It is shown that the controversies that surround this issue are motivated in general by an opposition to the neoclassical school, and in particular by that school's misuse of the notion of uncertainty. This misuse gives rise to the bounded rationality criticism of the optimization approach.

The chapter also offers some reflections upon the problem of the size of the firm. An analysis of the limitations of and stimulantes to dimensional growth is undertaken. We also discuss the objective or institutional nature of the factors counteracting the boundaries to a firm's dimensions, thereby obtaining knowledge of the degree of inevitableness of the dimensional growth of the firm - itself an important factor influencing the forms of competition.

\section{Abstract of Chapter 6}

This chapter treats one of the most elusive and, in a sense, mysterious phenomenon troubling both economists and economic operators: radical uncertainty. We first clarify the difference between expectations and uncertainty, with the former expressing the attempt to penetrate the inherent vagueness of the future, but the latter providing an expression of the degree of ignorance on future events. The importance of measuring the variable of uncertainty at sectoral level is insisted on, with the profits of BTS (Business Tendency Surveys) enabling the definition of various indicators of radical uncertainty. Finally, the chapter formalizes and estimates a simple model based on the interaction between uncertainty and innovation, examines the 
connected business cycle, and presents the econometric estimations of the model for Italy, the United Kingdom, France and Germany that indicate some differences between these countries in the operation of the phenomenon of dynamic competition.

\section{Abstract of Chapter 7}

This chapter inaugurates the passage from the theoretical side of our work to the reformations it implies or suggests and to the questions of political economy more generally. Specifically, we now combine our account of the process of dynamic competition, and the cyclical motion it implies, with the notion of particular historical phases of development; a combination disregarded by current economics and yet essential if we are to understand the changing character over time of growth processes and cycles. Our earlier treatment of institutions now facilitates a distinction between different historical phases as well as a perception of the circumstances of their advent. This supplies us with important knowledge concerning the basic contents of present and future ages as well as the changes over time of cyclical behavior. On such a basis we may trace an important and peculiar 'time arrow' in the generation of the economy: with the general conditions of development change those basic institutions that we denominate functional imperatives, which in turn causes the advent of new historical phases with corresponding organizational necessities - that is to say, a new world, the content of which we are able to perceive despite the unpredictable events that propel and characterize economic dynamics.

\section{Abstract of Chapter 8}

This chapter is dedicated to a theme that has generated substantial misunderstandings and yet long been a great source of inspiration for political economy, namely, Keynesian and post-Keynesian assumptions as to the leading role of demand in the economy and the definition of economic policies. As is well known, for over thirty years the Keynesian interpretation has constituted an important teaching able to promote high growth rates in developed countries. The chapter points out the appropriateness of demand led modeling in the phase of monopoly capitalism, which is characterized by high profits, low wages and unstable expectations that hold investment back well below profits, thereby causing a systematic deficiency of effective demand. But as we proceed to underline, such compatibility is far less apparent in more recent ages, which therefore demand an attempt to delineate a political economy more appropriate to newer phases of development. Nevertheless, the chapter shows that exposition of the conditions required by the functioning of Keynesian economics provides a useful exercise in understanding the requirements of completely different phases of development. For such understanding, the combination of the dynamic competition processes and the corresponding cyclical mutations, with the notion of phase of development, is very valuable.

\section{Abstract of Chapter 9}

We begin this chapter by noting how, in underdeveloped and dualistic economies, the operation of bottlenecks and diffused disequilibria prevents demand led policies from stimulating growth and development. We then point out that a main cause of the failure of Italian economic planning was its demand led nature and mistaken pretense of overcoming dualism through a programmatic approach. The chapter presents a formal dualistic model of the economy aimed at expressing some of the main traits of the Italian economy 
of that time. An econometric estimation of the model is provided, together with stability and sensitivity analysis and an enhancement of the in-sample predictive performance of the model.

\section{Abstract of chapter 10}

This chapter identifies some important monetary and financial variables and examines their changing role over the course of different phases of development and cyclical behavior. We pay attention, first of all, to money, highlighting its peculiar role in the phase of monopoly capitalism, characterized as it is by a chronic deficiency of effective demand.

We then turn to the controversy between Keynesians and monetarists, and point out the inappropriateness of both interpretations to the phase of consumeristic capitalism. We underline the importance, for the understanding of this phase, of the notion of 'nominal demand of money' and argue that, in the absence of money illusion, this endogenous character of money stimulates inflation and public debt.

The chapter then turns to the advent of the phase of financial capitalism, characterized by the dominance of international finance capital on a global scale, and points out that the inappropriateness of both Keynesian and monetarist interpretations is now exacerbated. But the full treatment of this point, as is pointed out, must be preceded by an analysis of interest rate, a main variable in the life and action of financial capital. We show that interest rate is an exogenous variable with little to do with the equilibrium between the supply and demand of capital, an unnecessary and pernicious variable at the heart of widespread speculation, which could be abolished through legal prohibition on a global scale.

The notion and the contents of phases of development are of crucial importance if we are to be able to delineate the basic reformations needed over the course of life of economic systems. A key step in satisfying such a need is a sound proposal concerning the organization of financial markets that aims to eliminate the domination of financial capital that is characteristic of the current phase of financial capitalism. Thus the final section of the chapter attempts to depict a national and international financial order not enslaving production but is rather at its service.

\section{Abstract of Chapter 11}

This chapter turns to the ethical dimension, primarily in relation to questions of social justice when combined with the operation of freedom and creativity. In other words, we consider here the functional need to combine diversity, which is essential to the expression of creativity, and social justice, which is essential to the extraction of the creative skills that are casually dispersed among a great number of people, so as to ensure a complete expression of individual skills and, hence, the realization of the connected evolutionary potential. It is clarified that this need also implies and requires the operation of some other important ethical principles, such as tolerance, free thinking, and the role of the individual. Consequently, these organizational and ethical needs appear to be endowed with an objective substance, rather than the subjective one imputed by ethical relativism.

In the chapter we perform a historical analysis of the presence and the role of equality and diversity in past civilizations, a great variety that substantially conditioned the evolutionary potential of the considered economic and social orders. Following this we consider the implications for our analysis of the advent of capitalism. The chapter concludes with a delineation of some relevant teachings on these matters by Keynes and Schumpeter, showing that the emphasis of the two authors on, respectively, the principle of effective 
demand and the role of entrepreneurship provides, for different reasons, interesting illumination on ethical and functional thinking.

\section{Abstract of Chapter 12}

This chapter sets out a concluding discussion of the need for profound reformations as demanded by the development process and the related succession of historical ages. If further highlights the important fact that the operation of spontaneous forces requires a parallel activity of control, which implies the interaction between spontaneous order and organization. What comes into view here is a growing affliction that troubles the modern world: some necessary institutions seem to legitimate capitalism as their progenitor, which induces an acceptance of a seemingly inevitable and growing inconsistency between capitalist civilizations and the present and coming phases of development.

To clarify this last and vital point: we here delineate a functional need that implies the overcoming of capitalism, but in doing so we are careful not to identify capitalism simply with the operation of the market and entrepreneurship. We denominate such a need the 'separation principle' between income distribution and production. Specifically, we advocate the construction of a market operating as a pure mechanism for the imputation of costs and efficiency, with the profit rate simply acting as a measure of the degree of success of entrepreneurial decision-making, but acting independently of the public or private character of the firm. And we give, in the final part of the chapter, a detailed exposition of the nature of such an institutional transformation, which in my opinion is an obligatory landing platform of modern dynamic economies. 